University of Rhode Island

DigitalCommons@URI

Open Access Dissertations

2014

\title{
THE EFFECTS OF ALCOHOL AND ATTENTION ON EYE MOVEMENTS, AND CHOICE REACTION TIME
}

Rouba A. Youssef

University of Rhode Island, rosyrouby@gmail.com

Follow this and additional works at: https://digitalcommons.uri.edu/oa_diss

\section{Recommended Citation}

Youssef, Rouba A., "THE EFFECTS OF ALCOHOL AND ATTENTION ON EYE MOVEMENTS, AND CHOICE REACTION TIME" (2014). Open Access Dissertations. Paper 283.

https://digitalcommons.uri.edu/oa_diss/283

This Dissertation is brought to you for free and open access by DigitalCommons@URI. It has been accepted for inclusion in Open Access Dissertations by an authorized administrator of DigitalCommons@URI. For more information, please contact digitalcommons-group@uri.edu. 
THE EFFECTS OF ALCOHOL AND ATTENTION ON EYE MOVEMENTS, AND CHOICE REACTION TIME

BY

ROUBA A. YOUSSEF

A DISSERTATION PROPOSAL SUBMITTED IN PARTIAL

FULFILLMENT OF THE REQUIREMENTS FOR THE DEGREE OF

DOCTOR OF PHILOSOPHY

IN

PSYCHOLOGY

UNIVERSITY OF RHODE ISLAND

2014 
DOCTOR OF PHILOSOPHY DISSERTATION

OF

ROUBA YOUSSEF

APPROVED:

Dissertation Committee:

Major Professor Charles E. Collyer

Lyn Stein

Manbir Sodhi

Nasser H. Zawia

DEAN OF THE GRADUATE SCHOOL

UNIVERSITY OF RHODE ISLAND

2014 


\begin{abstract}
This study examined the time course of alcohol's effect on two tasks performed concurrently, and on the tradeoff between them. It was hypothesized that alcohol impairs attentional focus, as well as the accuracy and reaction time to make directional choices, and so would induce a more severe tradeoff between tasks performed concurrently.
\end{abstract}

Equipment used in the study consisted of a device used to monitor eye movements, left and right light stimuli and a breathalyzer to measure blood alcohol levels. The sample for this project consisted of 46 men and women, between the ages of 21 and 30 years old. All participants were normative drinkers, and did not have any alcohol abuse or dependence problems.

Repeated measures were used to assess alcohol effects over time. Trade-off diagrams were used to test for differences in the dual-tasks. Participants in the control condition were not expected to show any differences in reaction time or eye fixations; these results are indicative of information processing. Differences in performance in one task or both tasks were interpreted as showing that alcohol slows total information processing.

Results are based on the ascending alcohol limb; more sedating effects are known to occur on the descending alcohol limb. Trade-off results showed impairment due to alcohol on the dual tasks. However, a more severe tradeoff between the tasks under alcohol was not present. Repeated measures analysis showed that the instructional effect was always found to vary significantly with time for reaction time; however; the dose by 
time interaction effect was not always present. In the latter timepoints — timepoints 4 and 5- the alcohol group performed worse even with the recognition task priority.

Future work can investigate the mediation of task performance and affective response in dual task performance. Acute tolerance might have allowed the participants to perform both tasks, and the motivational instructions might have also cued their attention to one task versus the other. A future study should investigate the end of the absorption-elimination curve to assess whether these changes remain the same or change over time. 


\section{ACKNOWLEDGEMENTS}

When I first worked on this project, I was excited to be running an alcohol study in the Engineering building at URI. It was not your typical social science lab. It had an eye tracking machine and all types of other industrial machines in the space. Running an experiment is not easy especially without many available resources but there were a lot of things that came together for me in this research project. I was able to recruit RA's who helped to keep me in engaged in the study, even when there were holdups or problems. They were always cognizant of their busy time schedules but worked hard in the research lab even when they had pressing deadlines of their own. Subject recruitment was not easy, even though this was an alcohol study! I am so thankful for the recruitment efforts that were mostly handled by my RA's. This project would not have been possible without their efforts and support with recruitment!

First I would like to thank my major professor and advisor, Dr. Charles Collyer, for his time and support in my journey to complete to my $\mathrm{PhD}$. I also want to thank my committee for providing such diverse and thoughtful comments throughout the process.

I would like to thank my parents, Fadia and Aslan. Without their hard work, dedication, and support this project and degree would not have been possible. I send a special thank you to my three sisters for motivating me and standing by me during my many stressful times.

Thanks to all my friends who helped keep the journey fun and knew when it was time to close the books and go out for a drink. Also, a big thanks to my roommates who were able to keep me motivated and awake in those late nights. Thank you to all the 
engineering students and staff, who answered all my questions and helped troubleshoot all the technical problems that I had along the way. Finally, I want to thank all my participants for being actively engaged in the process and keeping me engaged in the research process. 


\section{TABLE OF CONTENTS}

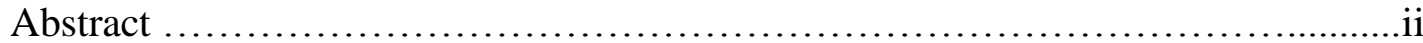

Acknowledgements...................................................

Table of Contents........................................................

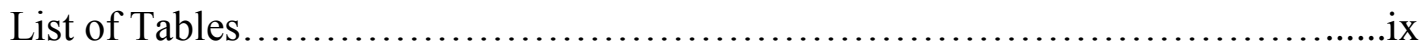

List of Figures...........................................................

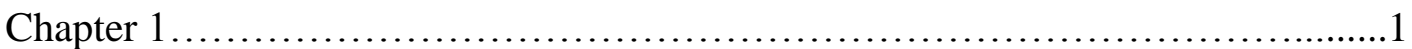

Introduction. ...................................................... 1

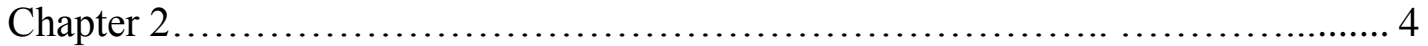

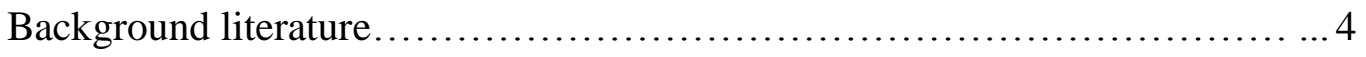

Effects of Alcohol..................................................... 4

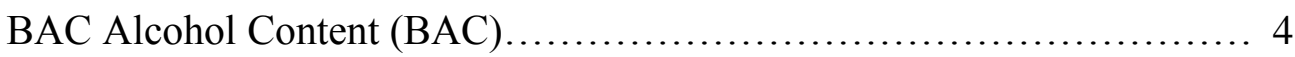

Effect of Alcohol on Visual Movements.............................6 6

Effects of Alcohol on Choice Response Time............................8

Effects of Alcohol on Motor Control.................................... 9

Effect of Alcohol on Cognition....................................... 10

Effect of Alcohol on Dual Tasks..................................... 13

Theory of Performance............................................. 14

Summary of Research.......................................... 15

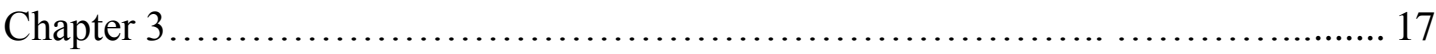

Method............................................................... 17

Recruitment of Participants...................................... 17

Study Sample.......................................................... 19 
Procedure.

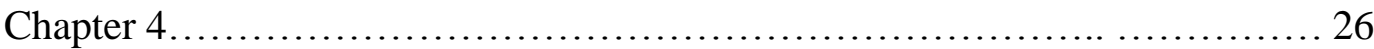

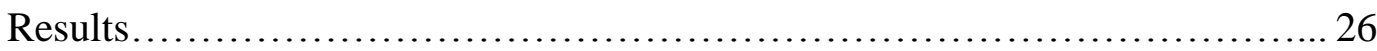

Participant Characteristics..................................................26

Alcohol Measures................................................ 30

Boxplots of BAC Levels.............................................31

Operationalization of Dual Tasks................................... 33

Summary Statistics and Correlations.................................34

Accuracy Response Plots for Eye Tracking Task....................42

Tradeoff Plots for the Dual Tasks..................................53

Self-report Plots of Performance...................................56

Mixed Anova Results............................................. 58

Other Factors................................................ 59

Sedation and Stimulation Plots.....................................61

Drinking Effects Plots.......................................63

Individual Differences Plot of the BAC Curve.......................67

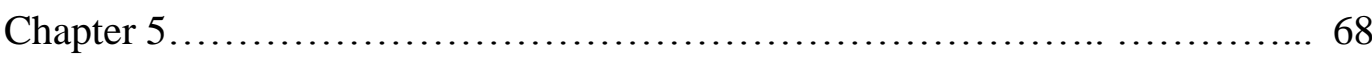

Discussion....................................................... 68

Summary of Findings........................................68

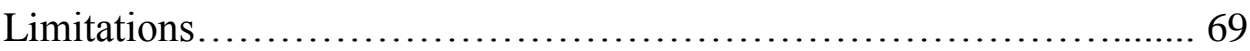

Future Research...............................................69

Appendices............................................................ 72

Appendix A: Multicultural Component.................................72 
Appendix B: Dosing algorithm.

Appendix C: Study Timeline and List of Measures........................75

Bibliography....................................................... 77 


\section{LIST OF TABLES}

Table

1. Frequency of stimuli for eye-tracking task

2. Sample demographics

3. Drinking behaviors survey

4. Drug use survey

5. BAC Alcohol levels and effects

6. BAC Alcohol levels and effects for subgroup

7. Summary and correlation matrix of reaction time for both placebo and alcohol groups (overall)

8. Summary and correlation matrix of reaction time for both placebo and alcohol groups (overall)

9. Summary statistics of reaction time for both placebo and alcohol group (Timepoint 3)

10. Summary statistics of reaction time for both placebo and alcohol group (Timepoint 4)

11. Summary statistics of reaction time for both placebo and alcohol group (Timepoint 5)

12. Correlation matrix for reaction time for placebo group (Timepoint 4) 37

13. Correlation matrix for reaction time for alcohol group (Timepoint 4) 37

14. Correlation matrix for reaction time for placebo group (Timepoint 5) 38

15. Correlation matrix for reaction time for alcohol group (Timepoint 5) 38 
16. Cumulative Distribution of Accuracy for Eye Tracking Task

17. Summary statistics and correlation matrix for Eye Tracking task (Timepoint 1)

18. Summary statistics and correlation matrix for Eye Tracking task (Timepoint 2) 


\section{LIST OF FIGURES}

Figure

Page

$\begin{array}{ll}\text { 1. Drinking restraint model } & 11\end{array}$

2. Light recognition task 22

3. Eye tracking task (Stimuli) 23

4. Eye tracking task (Task) 23

5. Distribution of Alcohol (BAC) levels across for timepoints 2 through 531

6. Distribution of Alcohol (BAC) levels across for timepoints 2 through 5 $\begin{array}{ll}\text { for subgroup } & 32\end{array}$

$\begin{array}{ll}\text { 7. Accuracy distance measure } & 40\end{array}$

8-27 Accuracy response plots 42

28. Trade-off plot (Timepoint 2) 53

29. Trade-off plot (Timepoint 3) 53

30. Trade-off plot (Timepoint 4) 54

31. Trade-off plot (Timepoint 5) 55

32-38 Self-report of performance for the dual tasks and individual tasks across the timepoints

39. Affective summary scores of sedation and stimulation for two alcohol participants across the timepoints

40. Affective summary scores of sedation and stimulation for two alcohol $\begin{array}{ll}\text { participants across the timepoints } & 61\end{array}$

41-48 Drinking effects plots 63-66

49. Individual differences plot 67 


\section{CHAPTER 1 \\ INTRODUCTION}

Alcohol impairs cognition through its sedating effect on many parts of the nervous system and related functions, such as sensory, motor, cognitive, and executive processes (Miyake, A., Friedman, N.P., Emerson, M.J., Witzki, A.H., \& Howerter, A., 2000). Although the effect is well-known, there is limited literature on how much impairment alcohol actually produces. Presumably, impairment is related to dose, with higher doses of alcohol producing more impairment. Similarly, dose varies with time as a result of ingestions, and absorption, and metabolism over time.

This study examined the time course of alcohol's effect on two tasks performed concurrently, and on the tradeoff between them. The research questions were: (1) how does alcohol affect a person's ability to perform two tasks at once? (2) how does this effect evolve over time as alcohol is metabolized?; (3) what is the performance tradeoff between tasks in response to changes in attentional instructions?; and (4) how does this tradeoff evolve over time as alcohol is metabolized?

This proposed research studied the effects of alcohol on attention, vision, and choice reaction time. The measures used include an eye tracking task to measure the ability to sustain tracking of a target stimulus, a directional response choice task to measure the ability to recognize discrete light flashes presented to the left or right, and a trade-off analysis using manipulation of task prioritization to obtain information about the ability to multitask (that is, perform the tracking and recognition tasks concurrently). It was hypothesized that alcohol impairs attentional focus, as well as the accuracy and reaction time to make directional choices, and induces a more severe tradeoff between 
tasks performed concurrently. This proposal aims included a diverse sample of men and women, as well as minority subjects. The study utilized sensory and cognitive measures that have little or no evidence of gender, racial, ethnic or other cultural bias (See Appendix A).

Two concurrent tasks, eye-tracking and light detection, were used to create a potential conflict in attention. Performance on these dual tasks depends on allocating attention, which may be easier to do when sober than when not. If eye tracking is prioritized first, then is eye tracking performance protected from the effect of alcohol? Does light detection suffer? Does it suffer only under the influence of alcohol? Alternatively, if the response to the light task is prioritized first, then is light detection performance protected from the effect of alcohol? Does eye tracking suffer? Does it suffer only under the influence of alcohol? Answers to these questions provide information on the effect of alcohol on the trade-off in performance between the two tasks.

In addition to measures of dual-task performance, the study included measures of cognitive functioning. Many cognitive measures are used to assess executive functioning. However, their inter-correlations are no greater than .40, and there are inconsistent significant effects (Miyake et al., 2000). The cognitive failure questionnaire (CFQ) (Broadbent et al., 1982) is used to measure lapses in everyday tasks. The inability to pay attention may be associated with several executive functions; the tasks chosen for this study are comparable to everyday tasks that we do in driving. For example, when are trying to change the radio station and keep our eyes on the road. 
The CFQ will be used to compare how lapses in everyday tasks may be related to changes in visual attention.

The dual-task paradigm presented subjects with competing attentional demands. It was expected that without alcohol, it would be easy for subjects to both track a visual target accurately and to perform well on the light detection task. Of interest was whether and how alcohol impairs performance on the two tasks, causes the two tasks to trade off more severely, or reveals an asymmetry in which one of the two tasks is preserved when alcohol limits the performance capacity of the subject overall. Finally, change in task impairment and task tradeoff between the two tasks change in relation to affective arousal and self-reported performance was examined. Results have important implications for information processing and how alcohol affects performance on dual tasks. 


\section{Chapter 2}

\section{Background Literature}

\section{Effects of Alcohol}

There has been an abundance of research examining the effects of alcohol (Fogarty \& Vogel-Sprott, 2002; Moskowtiz \& Sharma, 1974; Steele \& Josephs, 1990). Specifically, research has been conducted on how alcohol affects brain circuits that can slow visual processes and tasks (i.e. Schweizer e al., 2008, 1995; Tzambazis \& Stough, 2000). Behavioral signs of alcohol effects on the brain include difficulty walking, blurred vision, slurred speech and slowed reaction time. Different doses of alcohol are associated with different cognitive and physiological effects.

\section{Blood Alcohol Content (BAC)}

BAC levels of 0.02- 0.03 are known to cause feelings of euphoria and relaxation, with no loss of coordination. Levels of 0.04- 0.06 lead to feelings of relaxation, euphoria, and some impairment in reasoning and memory. Behaviors may become exaggerated and emotions are heightened at this level. Engaging in risky behavior become more frequent, since alcohol at these levels leads to disinhibited behavior. Levels of 0.07- 0.09 are associated with impairments in balance, speech, vision, reaction time and hearing. Inhibition of behaviors and emotional reactivity become extremely exaggerated. Alcohol levels of 0.10 or higher are associated with considerable impairment in motor coordination. Driving at elevated BAC levels is illegal due to these increased negative effects in motor functioning, but the legal limit varies somewhat from state to state. 
Several factors influence BAC, including amount consumed over time, absorption and metabolism rates, weight, gender, health, and food intake. BAC increase is less rapid with greater body weight and with food intake, and is less rapid in men than in women.

Laws vary by country for permissible BAC levels. The BAC thresholds range from $0.0 \mathrm{mg} / \mathrm{ml}$, or the level of "zero tolerance," to $0.8 \mathrm{mg} / \mathrm{ml}$. A World Health Organization (WHO, 2004) survey indicated $28 \%$ of countries had a BAC limit of (0.0 to $0.3 \mathrm{mg} / \mathrm{ml}$ ), $39 \%$ had a limit of $0.4-0.6 \mathrm{mg} / \mathrm{ml}$, and $26 \%$ adopted a limit of $0.6 \mathrm{mg} / \mathrm{ml}$ and above. Only $7 \%$ of countries did not have a maximum acceptable BAC level (WHO, 2004). The likelihood of traffic crashes and injury is higher in young people than older individuals at the same BAC levels (Peck et al., 2008). Therefore some countries impose a special BAC limit for young or less experienced drivers. Following ingestion of alcohol, BAC first rises and then falls. Numerous studies have shown that impairing effects of alcohol are greater on the rising part of the curve (e.g. Schweizer et al., 2006; Mellanby, 1919; Vogal-Sprott \& Fillmore, 1993). Both cognitive and motor decline have been confirmed; however, motor impairment is more severe on the declining part of the BAC curve. The motor skill tasks are usually pursuit rotor tasks. The cognitive tasks are usually information processing, working memory, or inhibition tasks. Mean change in performance is tracked across time and along the alcohol curve; motor skill impairment seems to track the blood alcohol curve, whereas the information processing task is more impaired on the initial test and does not seem to decline with the alcohol effect (Fogarty \& Vogal-Sprott, 2002) 
Alcohol consumption impairments include slowed reaction time and the individual's decreased ability to execute a range of motor tasks (Miller \& Low, 2001; Robinson \& Peebles, 1974). Driving requires precision, relying heavily on motor skills, reflexes and the ability to make quick decisions. Davis, Quimby, Odero, Gururaj, \& Hijar (2003) (ICAPS) state that the reaction time of an inebriated driver increases by 10 to $30 \%$ compared to a sober individual. Vision is blurred, and the judgment of distance, speed and hazards is impaired. A person's risk of being involved in a traffic crash, and likely injury severity, increase exponentially with the amount of alcohol consumed (Maple-Horvat et al., 2008). Drivers with BAC levels at .02-.04 g/ml are 1.4 times more likely to be involved in crashes than those who have not been drinking. Involvement in fatal crashes is much more likely for drivers with BAC levels over $.05 \mathrm{~g} / \mathrm{ml}$ than drivers who have not consumed alcohol (Fell \& Voas, 2006).

\section{Effect of Alcohol on Visual Movements}

The human visual system uses pursuit movements to track continuously moving targets. These movements are usually smooth and match the speed of the target. When there is no target to fixate on, or when the eye strays from its target, rapid movements of the eye from one fixation point to the next, called saccades, replace smooth pursuit. Saccadic movements are usually frequent, jerky and rapid. One of the tasks in this study will be tracking of an abruptly moving target. Measures of the eyes' performance will include fixations to target onset and saccade frequency (McSorley \& Findlay, 2001).

Alcohol has several effects on eye movements (Hill et al., 1990; Stapleton, Guthrie, \& Linnoila, 1986). A consistent decrease has been found in maximum saccadic velocity, but with no impairment in accuracy (Stapleton et al., 1986). The latency to 
initiate a saccade in response to a stimulus increases after alcohol administration. These effects have also been known to correlate with subjective reports of the degree of drunkenness, but not with blood or breath alcohol concentrations (e.g. Martin \& Earleywine, 1990). Alcohol impairs smooth pursuit movements and the number and/or amplitude of correcting saccades are increased; these movements are made to compensate for the reductions in the gain of smooth pursuit movements. Gain or saccadic accuracy was measured using the activity of the saccadic system (Barnes, G.R, 1984). Nystagmus is a pattern of compensatory eye movement that normally maintains visual fixation during head movements. Two types of abnormal nystagmus occur, lateral and positional, after drinking (Stapleton et al., 1986). Vengeance movements (crossing of the two eyes' lines of sight) are also affected; these movements are necessary to form a clear binocular view, alcohol decreases the efficiency of these movements (Stapleton et al., 1986). There is less known about how these effects change over time and how they follow the blood alcohol curve. More research is needed to address these changes.

There are mixed results regarding alcohol's effects on peripheral vision. There is debate over whether there is a reduction in the division of attention or actual sensory decline (Moskowitz \& Sharma, 1974). Hill and Toffolon (1990) concluded that no evidence supports the decline in visual acuity. Their work focused on the sensory and sensorimotor effects of alcohol. They used simple clinical tests to measure visual acuity, full peripheral visual fields, color vision tests, and tests of stereovision at a mean BAC level of .06. The change in the vertical visual field was significant, and moderately correlated with the $\mathrm{BAC}$ values, $\mathrm{r}=-.47, \mathrm{p}<0.025$. The constriction in both fields were more marked when the BAC level was highest. No results were found for visual acuity, 
color vision, or stereoacuity. A loss of accommodation, blurriness of letters from a distance, and convergence, looking at a black line closer and closer, were reduced at the highest BAC level. The authors claimed that these alterations are more indicative of the "spatial" visual pathway being more sensitive to alcohol than the "object" visual pathway (Hill \& Toffolon, 1990, p. 112). The spatial pathway is critical for the visual location of objects. Holdstock and de Wit (1999) investigated BAC levels of 0.04 and 0.08 in relation to mood effects on eye movements. Peak saccadic eye movement velocity (PSEV), saccadic latency, and smooth pursuit eye movement gain (SPG) were measured. Ethanol produced significant dose and time related impairments on PSEV and SPG in both the low and high BAC groups, but latency was not affected. These results were the same for the participants who reported stimulant or sedative-like effects of alcohol. Nicholson et al. (1995) also found the subjective effects were not correlated with the visual impairments after a moderate dose of alcohol. The lack of awareness for acute and long-term effects of alcohol is an important problem that can be addressed in visual attention studies.

\section{Effects of Alcohol on Choice Response Time}

Reaction time tasks have been commonly used to study behavioral response and information processing (Baayen \& Milin, 2010; Koelega, 1995). A choice response task requires participants to select a response from a set of possible responses. Other types of reaction time tasks include recognition reaction times, such as the go-no-go task, where participants are supposed to respond to one type of stimuli and ignore another type of stimuli. This is used to measure inhibition of signals. Both simple and complex reaction 
times were impaired by alcohol administration in an information processing study by Tzambazis and Stough (2000).

Post et al. (1996) summarized that alcohol impairs performance on tasks that place greater demand on visual spatial attention and disrupts the ability to shift attention during serial search. In two experiments, Post et al. (1996) measured simple reaction time using one task. Participants were required to respond to the onset of one of five targets and the offset of one of five illuminated targets. The size of the target displays was varied. Alcohol was used to measure the change on spatial attention. For the first experiment, mean reaction times were analyzed. Results showed that reaction time is longer when targets are distributed over a large display area. Post explained that the participants were keeping their attention sharply focused but moving that focused attention around the display like a spotlight, therefore, increasing reaction time. As for the effects of alcohol on this task, the researchers concluded that alcohol interfered with the ability to shift attention from one target location to another. Tzambazis and Stough (2000) agreed with these results, that alcohol does impair total information processing. The tradeoff used in this study will include a directional response choice task to measure the ability to recognize discrete light flashes presented to the left or right. If alcohol has an effect on the tradeoff, then we will expect to see an increase in choice response time for the alcohol group.

\section{Effect of Alcohol on Motor Control}

Alcohol is known to impair inhibitory control (Field et al., 2010). A moderate dose of alcohol at the .06 BAC level impairs inhibitory control on a stop signal and cued 
Go/No-Go tasks (e.g. Abroms, B.D. Fillmore, M.T., Marczinski, C.A., 2003; Field et al., 2010). Performance also becomes impaired at such doses. However, impaired speed or accuracy is not always accompanied to the target response. Thus, there is a selective disruption to inhibitory control and there is not an all-around decline in psychomotor performance. Alcohol impairments in inhibitory control may mediate alcohol priming effects on tolerance. Hull and Bond (1986) conducted a meta-analysis on the social and behavioral consequences of alcohol consumption, based on \#\#, three studies that examined the effects of alcohol and expectancy on motor performance the authors concluded that a detrimental effect of alcohol on motor performance is evident. They concluded that there was a significant heterogeneity across studies where motor performance was concerned but that the expectation of drinking alcohol is a more homogeneous effect. This heterogeneity is also extended to the lack of effects on physiology.

\section{Effect of Alcohol on Cognition}

Expectancies meditate the effects of alcohol, and are known to have cognitive effects of their own. For example, if a person has more to drink and has negative expectancies of their drinking behavior, they will not feel the positive effects of a similar amount of alcohol as much as a person who has positive expectancies. The alcohol expectancy scale (Brown, Christiansen, \& Goldman, 1987) is used to predict behavioral outcomes that are related to alcohol expectancies. Some of these factors include global positive change, sexual enhancement, arousal and aggression (Brown et al., 1987; Brown, Goldman, Inn, \& Anderson, 1980). 
In most of the cognitive literature, there are multiple explanations for understanding performance for different tasks. There are differing levels of performance, and dose intake can have a negative or positive effect for multiple reasons, whether the substance ingested is a placebo or an actual alcoholic substance.

These effects on performance are well-known and are relevant for the understanding of the development of alcohol related problems (Kreusch et al., 2013). Associations between alcohol expectancies and how they relate to alcohol-related problems have been found. Connor et al. (2000) (see Figure 1) developed the drinking restraint model that described cognitive and emotional properties associated with drinking. Cognitive properties of drinking can predict alcohol problems. These findings have implications for studying drinking in pre-dependent groups. Other techniques have looked at both explicit and implicit measures to test the effects of alcohol. The IAT or implicit-association test is used to detect the strength of a person's automatic association between mental representations of objects (concepts) in memory. It was used to classify an alcoholic drink or a soft drink as either neutral or stimulating. Participants had stronger expectancies of arousal and relaxation when they drank alcohol.

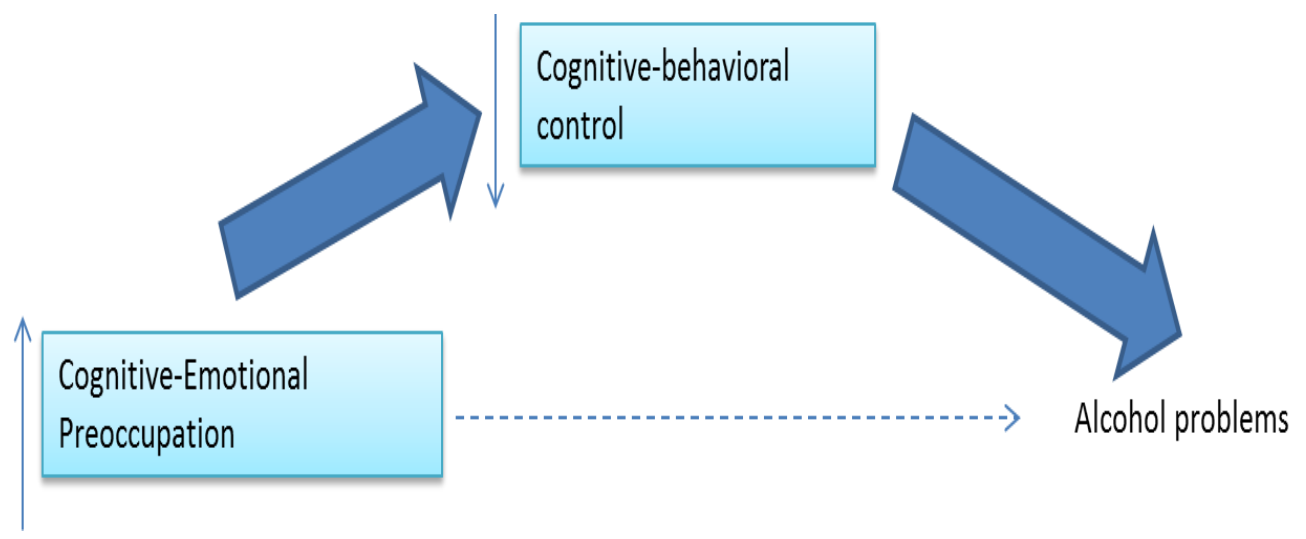

Figure 1. Drinking Restraint Model (Connor et al., 2000) 
Alcohol expectancies can both predict alcohol use and be considered an outcome. Sharkansky \& Finn (1998) discovered that alcohol expectancies were directly related to task performance. Differences in alcohol consumption across groups were mediated by expected effects of alcohol on task performance. Subjects scoring higher in disinhibition expected more negative effects of alcohol in the impairment condition.

A modified pursuit rotor task has been used in the assessment of visual-motor performance (George, Raynor, \& Nochajski, 1990, 1992). The participants were aided on the tasks by both motivational and auditory feedback signals. Different instructional sets of concentration were used in an effort to see if they helped counteract the effects of alcohol impairment. Participants self-reported concentration. Distractor tasks included magazine reading and digit spans, forward and backward. Alcohol was administered at a .06 level. Instructional sets "to concentrate very hard" and an auditory feedback signal were used to vary attentional effort in the task. Subjects were randomly assigned to six groups that differed in the instructional sets across four trials. Concentration was found to mediate alcohol resistance which defines the motivational characteristics of alcohol's effects. Instructional set also increased concentration, which then improved performance. Their results indicated that moderate levels of alcohol intoxication did not affect visualmotor tasks. Extrinsic conditions were influential, and concentration levels mediated performance levels. Similar variables and instructions were used in the present study to examine visual motor behavior. The verbal instructions provided during the tasks may help the participants with their concentration levels, as they divide their attention between the eye tracking and light recognition tasks. 


\section{Effect of Alcohol on Dual Tasks}

Alcohol has an effect on one's ability to attend to a task. Hunt et al. (2003) examined how covert and voluntary attention is linked or independent. Covert attention is the ability to attend to an area in the periphery without actually directing one's gaze toward it. Voluntary, or overt, attention is defined as directing one's gaze toward the location. Bottom-up (reflexive) and top-down (voluntary) processes are used to explain these changes in attention. Volitional orienting occurs more slowly, is more vulnerable to inhibition, and involves important differences in the representation of space, and is extremely sensitive to dual task demands. Dual tasks are especially important in testing for these effects (Navon \& Gopher, 1979). A dual task situation requires an individual to perform two tasks simultaneously. If performance suffers when both tasks are done simultaneously, then it is assumed that both tasks are competing for the same class of information processing resources in the brain. The problem has been given many different names, such as "attention switching," or "inattention blindness" or "tunnel vision." Dual approaches are an informative approach to the combined study of attention and substance use.

Tedstone and Coyle (2004) conducted a study comparing sober alcoholics to a matched non-alcoholic control-group on different aspects of attention. In the alcoholic group, impairments were found in all neuropsychological tests, a divided attention task, the Stroop task and other tasks that involve automatic processing. The selective attention task did not show any significant difference. The measures that were used included the Eriksen task and the Stroop task for selective attention, the divided attention tasks were a short vigilance task and a reaction time task. The current study will examine similar 
effects as participants are instructed to divide their attention between the eye tracking and the light recognition tasks. This will be done under alcohol and placebo conditions to see if alcohol has an effect on task performance and if this effect is found over time.

\section{Theory of Performance}

The theories described previously are important to the current study, as they offer support for attention as a multi-faceted variable that can be influenced by alcohol consumption. Important attentional components include visual attention, motor preparation, and reaction time.

Voluntary shifts in overt and covert visual attention can be studied using dual task designs. In differentiating both types of visual attention, volitional orienting occurs more slowly, is more vulnerable to inhibition, may involve important differences in the representation of space and is extremely sensitive to dual task demands (Abroms, Gottlob, \& Fillmore, 2006). This can entail a performance trade-off in dual tasks. Subjects may sacrifice speed in a secondary task, such as visual fixation, to maximize performance in a primary task, such as digit span. It is unclear whether speed alone was responsible for the performance trade-off. In three different experiments by Cheal and Lyon (1991), three processes were used to explain differences in the time course of peripheral versus central cuing effects on the discrimination of T-like characters. These three processes were orienting to the cue, engagement of attention, and an inhibitory process. Orienting to the cue was described as rapid and reflexive in the peripheral cue condition, whereas it is slower in the central cueing condition with the need of interpretation for the cue. Engagement of attention at the target location facilitates discrimination and results in an early rise in the alcohol curve with peripheral cues and a 
slower rise in the alcohol curve for central cues. An inhibitory process results in a drop in performance at long SOAs but only when a peripheral cue is used. Reaction time is shorter, or accuracy is better, at short intervals between cue onset and target onset (stimulus onset asynchrony, SOA) following a peripheral cue than following a central cue. The accuracy/SOA curve will rise more rapidly than with a central cue, and the two types of cues will provide equal facilitation if enough time is allowed for attention to arrive at the target location prior to target onset. Discrimination is delayed in the central cue condition in comparison to the peripheral cue condition. The difference between the peripheral and the central cue conditions is the time needed to decode and interpret the symbolic central cue. Another potential difference is that after the central cue is interpreted, attention is voluntarily oriented to target location, whereas orienting with a peripheral cue has been thought to be reflexive.

Previous literature clearly illustrated the relation between crash rates and BAC. In particular, this study focuses on visual attention post drinking, to determine the relative risk of crash rates. This study aims to understand the functioning of attention under the effects of alcohol.

\section{Summary of Research}

Previous research has clearly shown that alcohol will affect attention (Koelega, 1995; Abroms et al., 2006; Dougherty, Marsh, Moeller, Chokshi, \& Rosen, 2006). It is hypothesized that the results of the current study will most likely show that attention, executive control, and oculomotor control are involved in the dual-task experiment The research questions were: (1) how does alcohol affect a person's ability to perform two tasks at once?; (2) how does this effect evolve over time as alcohol is metabolized?; (3) 
what is the performance tradeoff between the tasks in response to changes in attentional instructions?; and (4) how does this tradeoff evolve over time as alcohol is metabolized? 


\section{Chapter 3}

\section{Method}

\section{Recruitment of Participants}

Participants were recruited using flyers and by word of mouth. Interested participants called the lab and were asked to answer a 15 minute telephone questionnaire. Exclusion criteria included having an Alcohol Use Disorders Identification Test (AUDIT) score greater than 15, a positive pregnancy test for females, having alcohol abuse and dependence problems, color blindness, and astigmatism.

Participants were first asked to complete an informed consent form, which included a detailed description of the study. The participants were informed that they were going to be randomized to an alcohol or placebo condition. The participant was first asked to complete a breath analysis test to make sure they did not have any alcohol in their system. They also had to answer questions about their diet. Female participants had to take a pregnancy test. Next, the participants were asked to fill out the demographics questionnaire, alcohol expectancy questionnaire, and the cognitive failures questionnaire. As soon as all the questionnaires were filled out, the participants began the lab part of the task. They were informed of the tasks they were going to perform over the next hour. They were also shown how to look straight ahead for the eye calibration and where to place their hands for the light recognition task. Prior to performing the baseline task, the participants filled out the biphasic alcohol scale and the visual analogue scale. Then they performed the eye tracking and light recognition task for the first time. Then they were administered their beverage. . Those receiving alcohol consumed the equivalent of about two to six drinks with the exact amount based on dosing algorithms adjusting for gender, age, height, and weight (see Appendix B). Participants in the 
alcohol condition were given 3-4 drinks to achieve a 0.08 BAC level and participants in the placebo condition received a non-alcoholic beverage. The alcoholic beverage consisted of three-parts orange juice, and one-part vodka ( 80 proof). The placebo beverage consisted of three -parts orange juice and one-part Rose's lime juice. A drop of vodka was floated on top of the placebo beverage to support blinding of the two conditions. Participants consumed between 12 to 40 ounces of beverage in approximately 15 minutes. This consumption period was followed by a breath analysis test. Their first breath alcohol level was taken 10 minutes after ingestion. The remaining 4 additional timepoints consisted of taking the biphasic analogue scale and the visual analogue scale and performing the dual tasks as well as getting breath alcohol readings. The drinking effects questionnaire was conducted at the end of the lab session; participants were asked to rate how much alcohol they thought they received and if they thought that the beverage affected their performance. The participants were debriefed at the end of the study, and the amount of alcohol they received was disclosed. For a more detailed description of measures, see procedures below.

The experiment was run by the experimenter and a research assistant. A breath alcohol rating and the preliminary questionnaires were followed by the eye calibration and motor task preparation. The participants placed their chin on the chin rest and focused their attention on the projector screen. Meanwhile their hands rested on the left and right response buttons for the reaction time task. Participants were asked to focus their visual attention on the screen, and to fixate on the center, upper left, upper right, lower left and lower right dots. The baseline timepoint required that the participant pay attention to both tasks at the same time. The following four timepoints required that the 
participant selectively pay attention to one task at a time. The participant received their beverage after the first timepoint. A breathalyzer rating was administered, and paper and pencil questionnaires were conducted before each timepoint. The biphasic alcohol effects questionnaire and the visual analogue scales were used to quantify any change in their stimulation and sedation ratings as well as how much they craved a drink. The participants who received alcohol were asked to remain in the waiting area until their blood alcohol level decreased to a .02 level. All participants had to complete the drinking effects questionnaire and were debriefed about the study before they left.

\section{Study Sample}

The sample for this project consisted of 46 men and women, between the ages of 21 and 30 years old. Participants were randomly assigned to receive either $.08 \mathrm{~g} / \mathrm{ml}$ dose of alcohol or a placebo dose of $0 \mathrm{~g} / \mathrm{ml}$. The first BAC reading was acquired 10 minutes after beverage consumption. The two tasks, eye tracking and light detection, were performed concurrently, but under three different attentional conditions differing in which task was given priority. In the eye condition, the eye tracking task was given attentional priority; the subject was told not to let her eye stray from the target. In the light condition, the directional light detection task was emphasized; the subject is told not to make any errors on the response keys. In the equal condition, emphasis was placed on both tasks; the subject was told that the eye tracking and recognition tasks were equally important. All 46 participants performed the equal condition task, and 23 participants performed the eye condition task first, and the other half (23) performed the light recognition task first. 
The two tasks were measured under three different attentional conditions, based on the following instructions from the research assistant, "I would like you to perform both the eye tracking and the light response task to the best of your ability." Keep your eye on the target at all times, and try not to make any errors in detecting the light"; or: "I would like you to prioritize the eye tracking, even if the light detection task suffers a bit. Try hard to keep your eye on the target all the time"; or: "I would like you to prioritize the light detection task even if the eye tracking task suffers a bit. Do not make any errors on the light detection task." A fixation screen was used to assess any changes in overt visual attention. The precision of fixation gaze was plotted against light recognition performance on a performance operating curve (POC) (see Figure 1) to examine how performance on the two different tasks related under different conditions.

In the eye tracking task, the horizontal and vertical stimuli were positioned in 8 different spots, with the center stimuli as the most frequent. Participants were asked to pay close attention to the stimuli on the screen. Each time a stimulus was projected on the screen, the participants were asked to fixate on that dot until the next stimulus was displayed. Although the stimuli were presented in the same locations for four minutes, the light recognition task was presented at the same time, and so participants had to pay attention to both tasks simultaneously. Some participants found the light task easier to follow than the eye tracking task. Also, some participants did not really fixate on the dots. Instead, they chose to prioritize the light recognition task. The eye tracking task seemed to be more automated whereas the light recognition task required controlled attention. 
Participants were required to track a moving target at 5 different time points. Measures of performance included fixations to target onset and saccade frequency. Minimum fixation duration is about 100 m.s. and typically ranges from 200 to 400 m.s. (Salvucci \& Goldberg, 2000). Saccade durations range from 20 to 40 m.s. Blinks were registered simply by recording the coordinates $\mathrm{x}=0$ and $\mathrm{y}=0$. Each saccade involves an acceleration to a peak velocity and a deceleration. Different algorithms and transformations are applied to the raw eye data. Good algorithms ensure valid fixation and saccade locations and durations (Salvucci \& Goldberg, 2000). The primary equipment for this experiment is an ISCAN ETL-500 eye tracker. The data were acquired at $60 \mathrm{~Hz}$. Different types of pattern recognitions i.e. time series and outlier analyses were performed in order to analyze the data and understand its statistical and distributional characteristics.

There are many different ways to analyze eye movements. In this study, the eye tracking task required the tracking of a moving target. Accuracy was used as a measure of performance for this task because attending to the spatial location of the target marked the subject's ability to attend to multiple locations while paying attention to the reaction time task. 


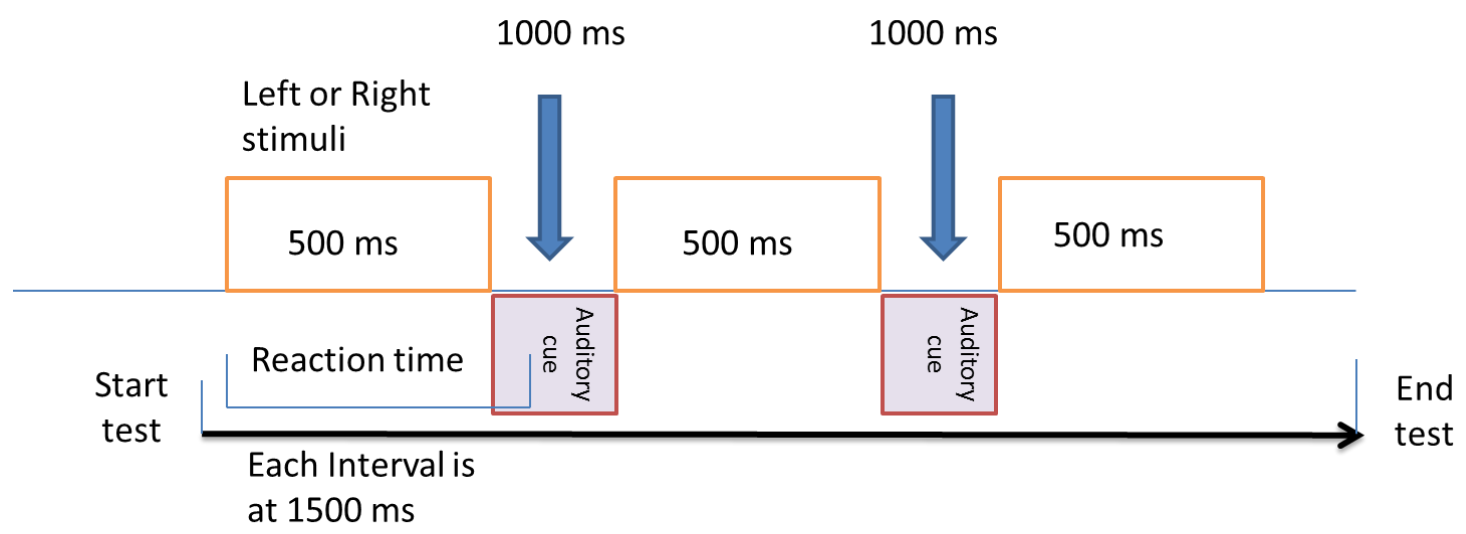

Total task time is $24000 \mathrm{~ms}$

Figure 2. Light recognition task.

In the Eye tracking task, as seen in Figure 3, subject tracked a dot that changed direction every 16 m.s. for a total of 24000 m.s. The dot moved in a random horizontal and vertical pattern and always returned to the center point in between the directional change. The sequence of dots is shown in Figure 4; table 1 includes the summary of eye tracking stimuli for each test block. In the light recognition task, as seen in Figure 2, participants pressed a left or right button when a left or right light was presented. Each stimuli lasted for 500 m.s. followed by a waiting interval of 1000 m.s. An auditory cue was sounded after each light stimulus was shown. The light recognition task ran in parallel with the eye tracking task for 24000 m.s. 
Figure 3. Eye tracking task, a target stimuli was presented every 16 m.s. for a total of 24000 m.s.
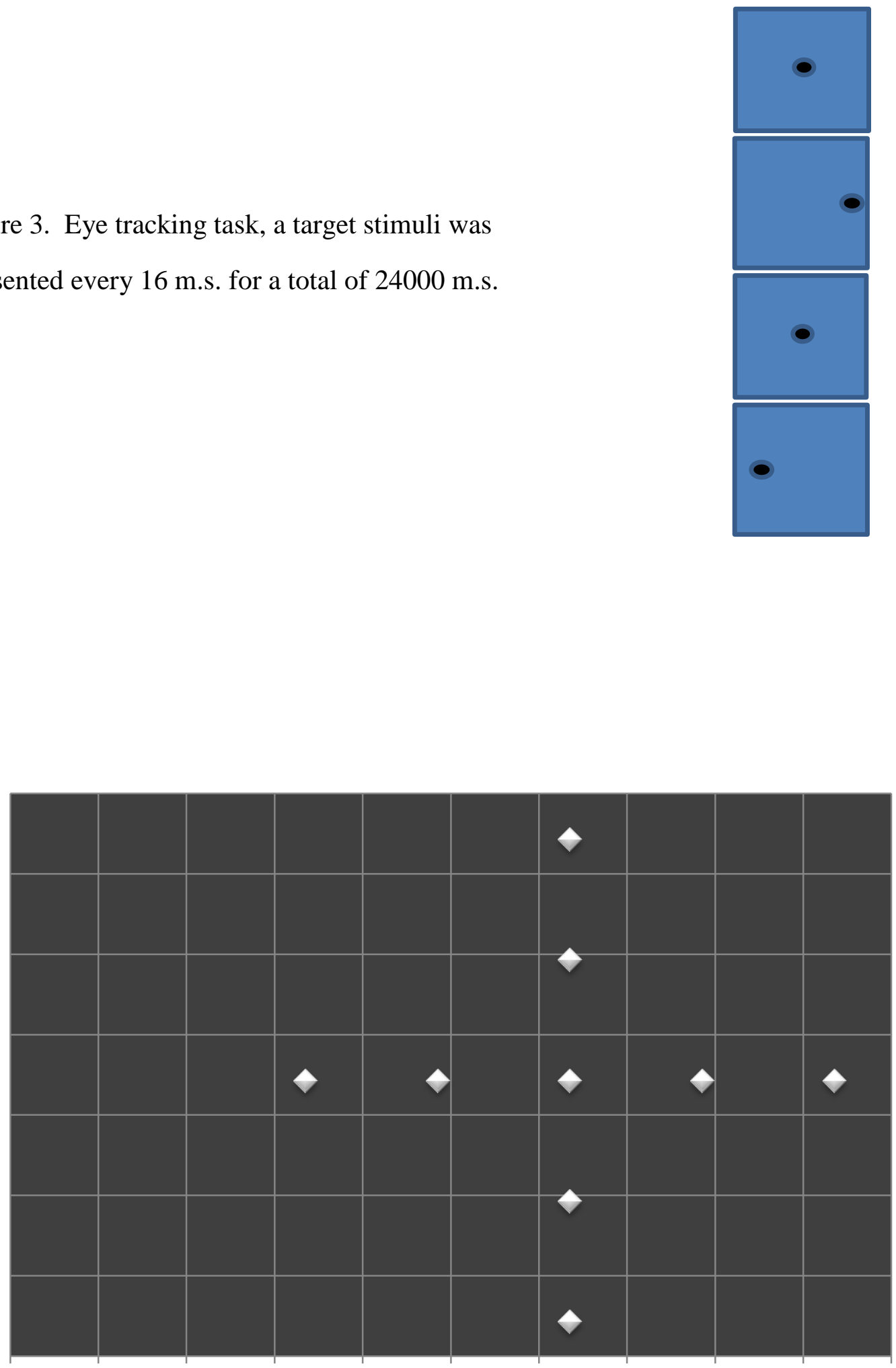

Figure 4. Eye tracking task stimuli parameters 
Table 1. Frequency of the eye tracking stimuli per block

\begin{tabular}{lllll}
\hline Xdot & Frequency & Percent & $\begin{array}{l}\text { Cumulative } \\
\text { frequency }\end{array}$ & $\begin{array}{l}\text { Cumulative } \\
\text { percent }\end{array}$ \\
\hline Left(2) & 3320 & 6.06 & 3320 & 6.06 \\
Left(1) & 3320 & 6.06 & 6640 & 12.12 \\
Center & 41667 & 76.06 & 48307 & 88.18 \\
Right(1) & 3154 & 5.76 & 51461 & 93.94 \\
\hline Right(2) & 3320 & 6.06 & 54781 & 100 \\
\hline Ydot & Frequency & Percent & Cumulative & Cumulative \\
& & & frequency & percent \\
\hline Lower(2) & 3320 & 6.06 & 3320 & 6.06 \\
\hline Lower(1) & 3320 & 6.06 & 6640 & 12.12 \\
\hline Center & 41501 & 75.76 & 48141 & 87.88 \\
\hline Upper(1) & 3154 & 5.76 & 51461 & 93.94 \\
Upper(2) & 3320 & 6.06 & 54781 & 100 \\
\hline
\end{tabular}

\section{Procedure}

Participants were randomly assigned to the two dosage groupsThe eye tracking and light detection tasks were carried out at baseline, 20, 30, 40 and 50 minute intervals. Subjects completed post-experimental measures to assess their level of perceived intoxication during the experiment as a manipulation check for deception concerning beverage administration. Following Sayette et al. (1994) we used a cut-off score of perceived intoxication to classify participants as successfully deceived about the alcoholic content of their beverage.

Paper and pencil tests were used to assess change in the subjective effects of alcohol intake at each timepoint. First, participants were screened using the Alcohol Use Disorders Identification Test (AUDIT) (Saunders, Aasland, Babor, de la Fuente, \& Grant, 1993). Baseline measures included: the demographics questionnaire, the alcohol expectancy questionnaire (AES) (Brown et al., 1987); and the Cognitive failures 
questionnaire (CFQ) (Broadbent et al., 1982). The biphasic alcohol scale (BAES)

(Martin et al., 1993) and the visual analogue scale (VAS) was administered at every time point during the experiment. The Drinking effects questionnaire is a self-report questionnaire that was used to validate the amount of alcohol the participant felt he/she received. This questionnaire was administered once at the end of the study.

Although all participants were normative drinkers, the biphasic alcohol scale was used to compare different expectancies on performance in the eye tracking and recognition tasks. Participants were fully debriefed about the study. Participants remained in our laboratory until their blood alcohol level, as measured by breath analysis testing, reached .02 or lower (the equivalent of about one drink). During this time, they were able to relax in a comfortable setting with snacks, water, computer and TV/DVD access. It was anticipated that the entire procedure would take anywhere from 1 to 2 hours (see Appendix C). 


\section{Chapter 4}

Results

Over 100 students between the ages of 21 and 30 years old were screened for this study. 54 students were eligible to participate; 6 were lost to follow-up and 2 participants did not complete the study. 46 participants were excluded for high AUDIT scores(9), prescription medication use(6), Astigmatism (18), a medical condition such as Diabetes(6), and problematic drinking behavior in the past year(7). A total of 46 students met the study requirements and completed the study as shown in Table 2. All participants were normative drinkers, defined as not drinking more than once or twice a week and not experiencing any alcohol abuse or dependence problems. Participants were asked to refrain from drinking 24 hours before the experiment in order to ensure that they had a $.00 \mathrm{BAC}$ before participating in the study. Items used to quantify drinking behavior included, in your lifetime, what was the maximum number of drinks you drank in the past 24 hours. All participants needed to score less than 15 on the AUDIT to qualify for the study. Nine participants scored above 15 and were not eligible to participate. Scores ranged from 0 to 30, with an average score of 9 . The AUDIT was used to screen for alcohol abuse and dependence. This is a common measure that is used in both research and clinical settings for screening alcohol use.

Summaries of alcohol and drug use of the eligible sample are shown in Tables 3 and 4. Most participants drank twice a week (33\%) and $2(35 \%)$ to $3(33 \%)$ drinks on a typical day. Binge drinking questions were used to screen frequent drinkers. A binge drinker is defined as drinking 4 (for males) -5 (for females) drinks on one occasion. Participants reported binge drinking; most participants drank 4 or 5 drinks in a 2 hour 
period only once per year (30\%) or 2 to 3 days a month (30\%). Binge drinking is occurring more and more on college campuses, these numbers again are fairly representative of a college population(Wechsler,Davenport, Dowdall, Moeykens, \& Castillo, 1994). Participants used Marijuana (78\%) most frequently; all the other recreational drugs were used very little.

Chi-square tests showed no overall differences between the alcohol dose groups, except for gender. The male participants reported drinking more in the past 12 months, $\chi^{2}(4, N=46)=10.29, p=.04$ twice a week for males and once a week for females; drinking more on a typical day, $\chi^{2}(4,46)=11.26, p=.02,\left(M_{\text {males }}=3\right.$ drinks, $M_{\text {females }}=2$ drinks $)$; and in their lifetime, $\chi^{2}(6, \mathrm{~N}=45)=15.14, p=.02,\left(M_{\text {males }} 8\right.$ to 11 drinks, $M_{\text {females }} 5$ to 7 drinks $)$. No age effects, after the age groups were collapsed to a 25 years old or younger age group and a greater than 25 years old age group, were found to be significant for any of the drinking pattern questions.

Table 2

Participant Characteristics

$(\mathrm{N}=46)$

Age

$21-25$

26-30 n

$33(71.74 \%)$

$13(28.26 \%)$

\section{Gender}

$\begin{array}{lll}\text { Male } & 26 & (56.52 \%) \\ \text { Female } & 20 & (43.38 \%)\end{array}$




\begin{tabular}{clll}
\hline \hline Race & & & \\
& Caucasian & 35 & $(77.78 \%)$ \\
Asian & 3 & $(6.67 \%)$ \\
Black & 3 & $(6.67 \%)$ \\
Other & 4 & $(8.89 \%)$ \\
Missing & 1 & \\
& & &
\end{tabular}

Ethnicity

$\begin{array}{lll}\text { Non-Hispanic } & 43 & (95.56 \%) \\ \text { Hispanic } & 3 & (4.44 \%)\end{array}$

Education

Still in school $34 \quad(73.91 \%)$

No 12 (26.09\%)

\section{Corrected Vision}

$\begin{array}{lll}\text { Yes } & 17 & (36.96 \%) \\ \text { No } & 29 & (63.04 \%)\end{array}$

Smoker

$\begin{array}{lll}\text { Yes } & 5 & (11.36 \%) \\ \text { No } & 39 & (88.64 \%)\end{array}$

AUDIT score

$\begin{array}{lll}<8 & 25 & (54.35 \%) \\ 8-15 & 21 & (45.65 \%)\end{array}$

Table 3

Alcohol use Survey

Past 12 months how often had a drink containing alcohol

2 to 3 times a month

$8 \quad(17.39 \%)$

once a week

$12(26.09 \%)$

twice a week

$15(32.61 \%)$

3 to 4 times a week

$8 \quad(17.39 \%)$

5 to 6 times a week

$3(6.52 \%)$

Number of drinks on a typical day

Frequency

1 drink

$4 \quad(8.7 \%)$ 
2 drinks

3 drinks

$15 \quad(32.61 \%)$

4 drinks

8 to 11 drinks

$8 \quad(17.39 \%)$

$3(6.52 \%)$

Largest amount of drinks in 24 hours

\section{4 drinks}

Frequency

5to 7 drinks

8 to 11 drinks

$16 \quad(34.78 \%)$

$15(32.61 \%)$

12 to 17 drinks

$9(19.57 \%)$

18 to 23 drinks

$1 \quad(2.17 \%)$

Last 12 months have more than 4 or 5 drinks in 2 hour period

0 days in the past year

Frequency

1 or 2 days in the past year

3 to 11 days in the past year

one day a month

$7(15.22 \%)$

2 to 3 days a month

$6 \quad(13.04 \%)$

one day a week

$14 \quad(30.43 \%)$

2 days a week

$2(4.35 \%)$

$2(4.35 \%)$

\section{Table 4}

Drug Use Survey

Have you ever used the following:

Frequency
Yes

$36(78.26 \%)$
$9 \quad(19.57 \%)$

36

$9.57 \%)$
Frequency

No
Marijuana

Amphetamines, other stimulants
10

$(21.74 \%)$

$37 \quad(80.43 \%)$ 
Cocaine, Crack

Opiates (heroin, opium, morphine, codeine)

\section{Hallucinogens}

Inhalants

Barbiturates, "other downers"
$5(10.87 \%)$

$1 \quad(2.17 \%)$

$11(23.91 \%)$

$2(4.35 \%)$

$2(4.35 \%)$
41

45

$(97.83 \%)$

$35 \quad(76.09 \%)$

$44 \quad(95.65 \%)$

$44 \quad(95.65 \%)$

In order to control for beverage rate consumption, several events had to take place prior to the alcohol administration. Participants were asked if they had any alcohol before starting the experiment. An initial BAC was then used to test if they had any alcohol in their system. One participant had a baseline BAC that was greater than .00 and was rescheduled for another study time. Participants were also asked several questions about their eating and sleeping schedules before coming in to participate. All participants had to agree that they would not eat or drink anything other than the provided beverage until the end of the experiment.

Each participant was provided with a beverage that did or did not include alcohol. All participants had to complete the beverage consumption in 15 minutes. Participants were also instructed to not chug their drinks but to try to pace themselves in drinking the total amount. Although alcohol levels were consistently taken every ten minutes, the single blind design was kept throughout the total experiment. However, the maximal value of a $.08 \mathrm{BAC}$ was not always reached. The range of the actual alcohol dose varied from $.02 \mathrm{~g} / \mathrm{ml}$ to $.088 \mathrm{~g} / \mathrm{ml}$, with the most frequent average in the range of $.04 \mathrm{~g} / \mathrm{ml}$ and $.05 \mathrm{~g} / \mathrm{ml}$ (Table 5). The boxplot in figure 5 shows a slight decline in the alcohol dose 
after the peak level in timepoint 2. Seven participants had a range that was greater than this overall range. This subgroup was flagged in order to describe if changes in the BAC were related to changes in subjective intoxication. Patterns of subjective intoxication might be related to acute tolerance. The average BAC level for this subgroup was at .06 $\mathrm{g} / \mathrm{ml}$ (Table 6). The boxplot for this subgroup also shows a slight decrease in the overall BAC level after the peak level in timepoint 2 (Figure 6).

\begin{tabular}{cccccc}
\hline Timepoint & $\mathbf{N}$ & Mean & (SD) & Minimum & Maximum \\
\hline $\mathbf{2}$ & 18 & 0.055 & $(0.02)$ & 0.019 & 0.078 \\
$\mathbf{3}$ & 18 & 0.052 & $(0.01)$ & 0.027 & 0.073 \\
$\mathbf{4}$ & 18 & 0.054 & $(0.01)$ & 0.031 & 0.072 \\
$\mathbf{5}$ & 19 & 0.056 & $(0.01)$ & 0.037 & 0.074 \\
\hline
\end{tabular}

Table 5. Summary statistics of BAC levels over time for alcohol group

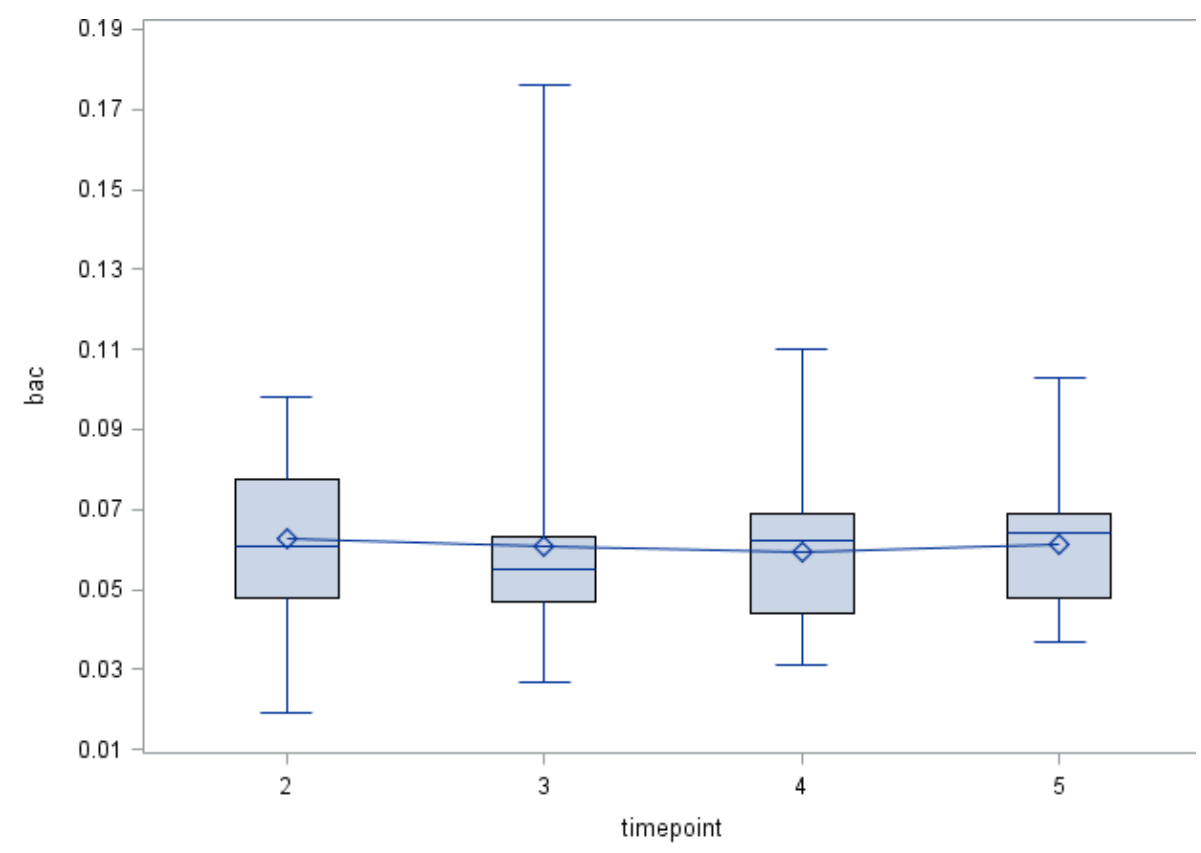


Figure 5. Distribution of Alcohol (BAC) levels across for timepoints 2 through 5

\begin{tabular}{rrrrr}
\hline Timepoint & \multicolumn{1}{c}{ Mean } & (SD) & Minimum & Maximum \\
\hline $\mathbf{2}$ & 0.063 & $(0.02)$ & 0.019 & 0.098 \\
$\mathbf{3}$ & 0.061 & $(0.03)$ & 0.027 & 0.176 \\
$\mathbf{4}$ & 0.060 & $(0.02)$ & 0.031 & 0.110 \\
$\mathbf{5}$ & 0.061 & $(0.02)$ & 0.037 & 0.103 \\
\hline
\end{tabular}

Table 6. Summary statistics of BAC levels over time for subgroup with higher than average BAC levels

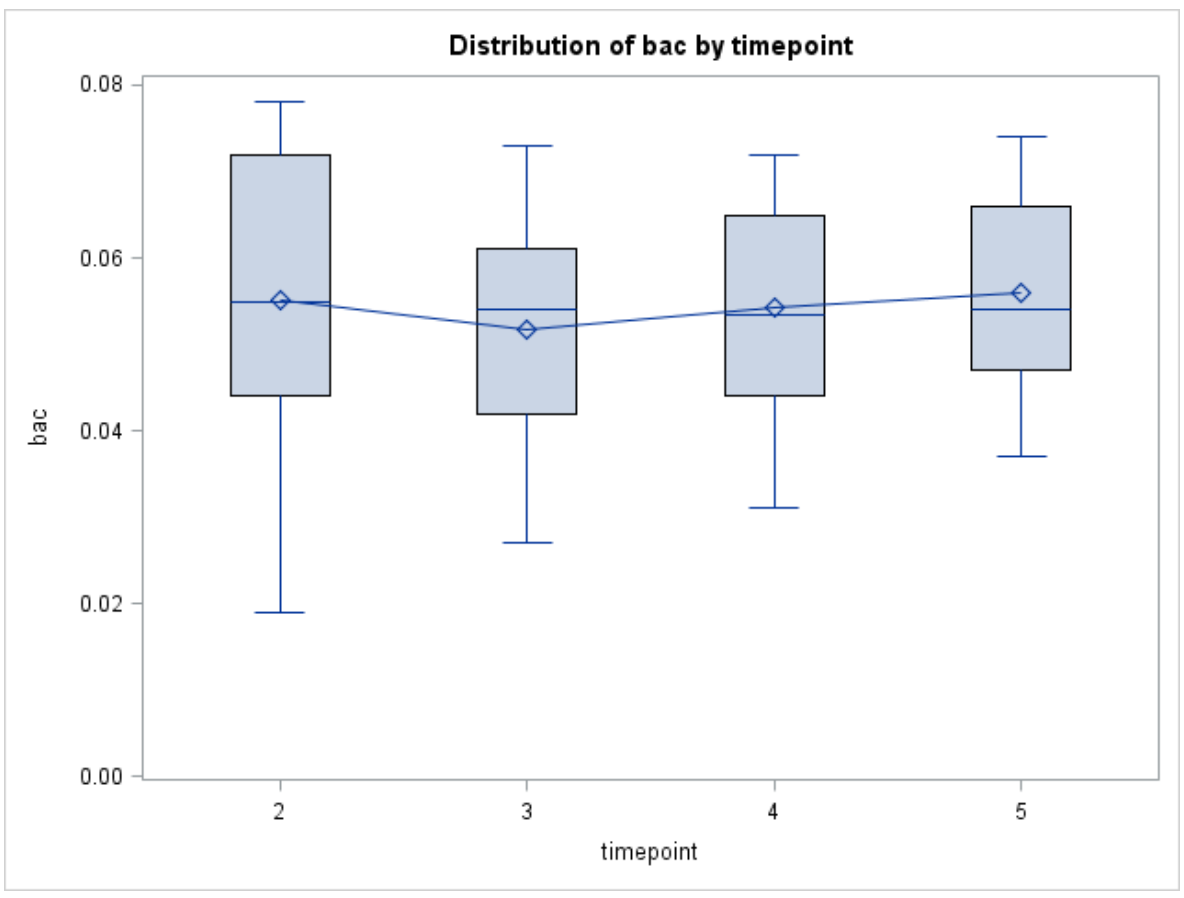

Figure 6. Distribution of Alcohol (BAC) levels across for timepoints 2 through 5 for subgroup

These acquired breath alcohol rates were not consistent across the alcohol dosed participants. The alcohol dosing equation used, controlling for the beverage rate consumption, and inclusion criteria, should have limited the individual variation in dose response. To account for differences in alcohol response, the rate of consumption can be 
used to measure the difference between the beginning of drinking to peak values, and also to measure the descending limb between peak values and return to baseline(Martin, 1990). In this study, the complete experimental period only took place during the peak and plateau of the alcohol curve. Although functional decline is more observable on the ascending limb of alcohol, the effects of sedation are important to observe on the descending limb. The effects of alcohol over time might have been greater if the secondary limb of the dose response was observed.

We used two main measures to study the effects of alcohol on attention, vision, and choice reaction time. We hypothesized that eye tracking and reaction time are valid measures of dual task performance and are reliable indicatorsof attention. Light stimuli were positioned symmetrically within the participant's view. The left stimulus was composed of a green light and the right stimulus was composed of a red light; both were presented in a random sequence that lasted for four minutes. Each light was presented for a total of $200 \mathrm{~m} . \mathrm{s}$. Participants had $5000 \mathrm{~m} . \mathrm{s}$. to respond to each light by pressing a left or right button. In between each light stimulus, a beeping sound was used to cue the next signal. There was a 1000 m.s. pause before the next signal. Participants were mostly accurate (99\%) in their responses to both stimuli. The overall average response time for the light recognition task was 491 m.s. with a standard deviation of 133 m.s. The average response time for the left stimulus was 223 m.s. and the right stimulus was 218 m.s. (Table 7). Errors were averaged into the overall response time. Errors were not specific to the left or right lights of the task. Overall reaction time was highly correlated with the left and right reaction times; the left and right response times were moderately correlated with each other(Table 8). 
TABLE 7. Summary Statistics and Correlation Matrix of Reaction Time Tasks (Across Time)

\begin{tabular}{ccccc}
\hline \multicolumn{5}{c}{ Simple Statistics of Reaction Time Task (N = 208) } \\
\hline $\begin{array}{c}\text { Reaction } \\
\text { Time Task }\end{array}$ & Mean & Std Dev & Minimum & Maximum \\
\hline $\begin{array}{c}\text { Reaction } \\
\text { Time } \\
\text { (Overall) }\end{array}$ & 491.12 & 133.20 & 260.19 & 1128.00 \\
$\begin{array}{c}\text { Reaction } \\
\text { Time (Left) } \\
\text { Reaction } \\
\text { Time } \\
\text { (Right) }\end{array}$ & 222.54 & 53.58 & 107.56 & 418.29 \\
\end{tabular}

Table 8. Correlation Matrix of Reaction Time Task $(\mathrm{N}=208)$

\begin{tabular}{lccc}
\hline $\begin{array}{c}\text { Reaction } \\
\text { Time Task }\end{array}$ & 1 & 2 & 3 \\
\hline $\begin{array}{l}\text { 1. Reaction } \\
\text { Time } \\
\text { (Overall) }\end{array}$ & - & & \\
$\begin{array}{l}\text { 2. Reaction } \\
\text { Time (Left) }\end{array}$ & $0.53^{*}$ & - & \\
$\begin{array}{l}\text { 3. Reaction } \\
\text { Time }\end{array}$ & $0.56^{*}$ & $0.37^{*}$ & \\
(Right) & & & \\
\end{tabular}

*All Correlations are significant at the <.0001 level (2tailed).

Incorrect responses occurred minimally. Error in this task included pressing the left button when the right stimuli was on, or the right button when the left stimuli was on. These errors occurred less than $1 \%$ of the time. There are only about 162 stimuli or $1 \%$ that were timed out. The timeouts were equivalent to $5000 \mathrm{~m}$.s. each. Those participants who had timeouts in the baseline run were more likely to have timeouts in the consecutive runs. The stimuli were presented continuously for a total of 4 minutes for 
each block of time. An average of 34 left and 25 right lights occurred during each test block. Since accuracy of response was not different across subjects, the actual response time was used as the performance measure. Average reaction time was compared using $z$-scores, to standardize the reaction time for the recognition performance task. Those participants' scores that had a standard deviation greater than 3 were not included in the remaining analyses. Summary statistics for the both groups and for the timepoints 3 to 5 are presented in Tables 9-11. Correlation matrices for timepoints 4 and 5 (Tables 12-15) explain that the light recognition response rates are associated across time. For timepoint 4 , overall reaction time was significantly correlated with left reaction time and right reaction time $(\mathrm{r}=.81, \mathrm{p}<.0001)$ in the placebo group. In the alcohol group, overall reaction time was also correlated with left and right reaction time $(\mathrm{r}=.58, \mathrm{p}<.05)$; however, right reaction time was not significantly related with left reaction time. For timepoint 5 , right reaction time was not significantly associated with left reaction time in the placebo group. In the alcohol group, left reaction time was not significantly associated with overall reaction time.

TABLE 9. Summary Statistics of Reaction Time Tasks (Timepoint 3)

\begin{tabular}{cccccc}
\hline \multicolumn{5}{c}{ Simple Statistics of Reaction Time Task } \\
\hline $\begin{array}{c}\text { Reaction } \\
\text { Time Task }\end{array}$ & Group & Mean & Std Dev & Minimum & Maximum \\
\hline $\begin{array}{c}\text { Reaction } \\
\text { Time } \\
(\text { Overall })\end{array}$ & & & & & \\
& $\begin{array}{c}\text { Placebo } \\
\text { (N=18) }\end{array}$ & 473.38 & 106.27 & 320.27 & 648.86 \\
& $\begin{array}{c}\text { Alcohol } \\
(\mathrm{N}=24)\end{array}$ & 475.47 & 126.78 & 314.47 & 882.54 \\
$\begin{array}{c}\text { Reaction } \\
\text { Time } \\
\text { (Left) }\end{array}$ & & & & &
\end{tabular}




\begin{tabular}{|c|c|c|c|c|c|}
\hline & $\begin{array}{l}\text { Placebo } \\
(\mathrm{N}=18)\end{array}$ & 227.51 & 42.68 & 154.39 & 293.16 \\
\hline \multirow{4}{*}{$\begin{array}{l}\text { Reaction } \\
\text { Time } \\
\text { (Right) }\end{array}$} & $\begin{array}{l}\text { Alcohol } \\
(\mathrm{N}=24)\end{array}$ & 218.29 & 50.40 & 107.56 & 315.85 \\
\hline & & & & & \\
\hline & $\begin{array}{c}\text { Placebo } \\
(\mathrm{N}=18)\end{array}$ & 217.38 & 58.64 & 122.53 & 355.70 \\
\hline & $\begin{array}{l}\text { Alcohol } \\
(\mathrm{N}=24)\end{array}$ & 213.48 & 51.76 & 133.87 & 358.17 \\
\hline \multicolumn{6}{|c|}{ TABLE 10. Summary Statistics of Reaction Time Tasks (Timepoint 4) } \\
\hline \multicolumn{6}{|c|}{ Simple Statistics of Reaction Time Task } \\
\hline $\begin{array}{c}\text { Reaction } \\
\text { Time } \\
\text { Task } \\
\end{array}$ & Group & Mean & Std Dev & Minimum & Maximum \\
\hline \multicolumn{6}{|l|}{$\begin{array}{l}\text { Reaction } \\
\text { Time } \\
\text { (Overall) }\end{array}$} \\
\hline & $\begin{array}{l}\text { Placebo } \\
(\mathrm{N}=17)\end{array}$ & 472.53 & 87.78 & 374.44 & 693.16 \\
\hline & $\begin{array}{l}\text { Alcohol } \\
(\mathrm{N}=24)\end{array}$ & 478.04 & 158.57 & 309.05 & 1020.00 \\
\hline \multicolumn{6}{|l|}{$\begin{array}{c}\text { Reaction } \\
\text { Time } \\
\text { (Left) }\end{array}$} \\
\hline & $\begin{array}{l}\text { Placebo } \\
(\mathrm{N}=17)\end{array}$ & 221.81 & 43.75 & 179.92 & 352.21 \\
\hline & $\begin{array}{l}\text { Alcohol } \\
(\mathrm{N}=24)\end{array}$ & 222.51 & 66.74 & 124.82 & 370.79 \\
\hline \multicolumn{6}{|l|}{$\begin{array}{l}\text { Reaction } \\
\text { Time } \\
\text { (Right) }\end{array}$} \\
\hline & $\begin{array}{l}\text { Placebo } \\
(\mathrm{N}=17)\end{array}$ & 230.86 & 51.46 & 156.48 & 340.95 \\
\hline & $\begin{array}{l}\text { Alcohol } \\
(\mathrm{N}=24)\end{array}$ & 217.79 & 51.99 & 118.69 & 350.55 \\
\hline
\end{tabular}

TABLE 11. Summary Statistics of Reaction Time Tasks (Timepoint 5) Simple Statistics of Reaction Time Task 


\begin{tabular}{|c|c|c|c|c|c|}
\hline $\begin{array}{l}\text { Reaction } \\
\text { Time Task }\end{array}$ & Group & Mean & Std Dev & Minimum & Maximum \\
\hline \multicolumn{6}{|l|}{$\begin{array}{l}\text { Reaction } \\
\text { Time } \\
\text { (Overall) }\end{array}$} \\
\hline & $\begin{array}{l}\text { Placebo } \\
(\mathrm{N}=18)\end{array}$ & 466.43 & 91.14 & 320.10 & 668.67 \\
\hline & $\begin{array}{l}\text { Alcohol } \\
(\mathrm{N}=24)\end{array}$ & 521.47 & 171.21 & 309.29 & 1128.00 \\
\hline \multicolumn{6}{|l|}{$\begin{array}{l}\text { Reaction } \\
\text { Time } \\
\text { (Left) }\end{array}$} \\
\hline & $\begin{array}{l}\text { Placebo } \\
(\mathrm{N}=18)\end{array}$ & 221.87 & 62.32 & 157.41 & 418.29 \\
\hline & $\begin{array}{l}\text { Alcohol } \\
(\mathrm{N}=24)\end{array}$ & 227.10 & 50.18 & 151.48 & 312.81 \\
\hline \multicolumn{6}{|l|}{$\begin{array}{l}\text { Reaction } \\
\text { Time } \\
\text { (Right) }\end{array}$} \\
\hline & $\begin{array}{l}\text { Placebo } \\
(\mathrm{N}=18)\end{array}$ & 216.76 & 53.95 & 161.45 & 365.95 \\
\hline & $\begin{array}{l}\text { Alcohol } \\
(\mathrm{N}=24)\end{array}$ & 212.13 & 56.16 & 139.37 & 343.00 \\
\hline
\end{tabular}

Table 12. Correlation Matrix of Reaction Time Task ( Timepoint 4 Placebo)

\begin{tabular}{lccc}
\hline Reaction Time Task & 1 & 2 & 3 \\
\hline $\begin{array}{l}\text { 1. Reaction Time } \\
\text { (Overall) }\end{array}$ & - & & \\
$\begin{array}{l}\text { 2. Reaction Time } \\
\text { (Left) }\end{array}$ & $0.81^{*}$ & - & \\
$\begin{array}{l}\text { 3. Reaction Time } \\
\text { (Right) }\end{array}$ & $0.84^{*}$ & $0.65^{* *}$ & - \\
\hline
\end{tabular}

*All Correlations are significant at the <.0001 level (2-tailed).

**All Correlations are significant at the <.05 level (2-tailed).

Table 13. Correlation Matrix of Reaction Time Task (Timepoint 4 Alcohol)

\begin{tabular}{cccc}
\hline $\begin{array}{c}\text { Reaction Time } \\
\text { Task }\end{array}$ & 1 & 2 & 3 \\
\hline
\end{tabular}


1. Reaction Time

(Overall)

2. Reaction Time

(Left) 0.58*

3. Reaction Time

$\begin{array}{lll}\text { (Right) } & 0.58 * & 0.20\end{array}$

*All Correlations are significant at the <.05 level (2-tailed).

Table 14. Correlation Matrix of Reaction Time Task (Timepoint 5 Placebo)

\begin{tabular}{lccc}
\hline \multicolumn{1}{c}{$\begin{array}{c}\text { Reaction Time } \\
\text { Task }\end{array}$} & 1 & 2 & 3 \\
\hline $\begin{array}{l}\text { 1. Reaction Time } \\
\text { (Overall) }\end{array}$ & - & & \\
$\begin{array}{l}\text { 2. Reaction Time } \\
\text { (Left) }\end{array}$ & $0.62^{*}$ & - & \\
$\begin{array}{l}\text { 3. Reaction Time } \\
\text { (Right) }\end{array}$ & $0.76^{*}$ & 0.15 & - \\
\end{tabular}

*All Correlations are significant at the <.01 level (2-tailed).

Table 15. Correlation Matrix of Reaction Time Task (Timepoint 5 Alcohol)

\begin{tabular}{lccc}
\multicolumn{1}{c}{$\begin{array}{c}\text { Reaction Time } \\
\text { Task }\end{array}$} & 1 & 2 & 3 \\
\hline $\begin{array}{l}\text { 1. Reaction Time } \\
\text { (Overall) }\end{array}$ & - & & \\
$\begin{array}{l}\text { 2. Reaction Time } \\
\text { (Left) }\end{array}$ & 0.37 & - & \\
$\begin{array}{l}\text { 3. Reaction Time } \\
\text { (Right) }\end{array}$ & $0.49 * *$ & $0.65^{*}$ & - \\
\end{tabular}

*All Correlations are significant at the <.0001 level (2-tailed).

**All Correlations are significant at the <.05 level (2-tailed).

The eye tracking task used 9 dot positions that were randomly presented on the projector screen. Participants were instructed to direct their eyes to the dots as they 
flashed on the screen. The dots were presented in a horizontal and vertical pattern. The Euclidean distance was calculated between the actual position of the dot and the eye position of each participant (see Figure 7). The distance of 300 was used as a criterion to determine the overall accuracy of visual fixations (Table 16); a distance between eye and target of 300 or less was regarded as a "success". The first timepoint had an average success rate at 44 percent with the maximum accuracy at 77 percent. No prioritization of attention occurred for timepoint 1. Across all the timepoints, average success rate was 43 percent with the maximum accuracy at 83 percent. As noted, the recognition task yielded high accuracy. However, the eye tracking task was more difficult and showed more varied performance. The center points were the easiest to detect, at an average success rate of $49 \%$. Interestingly, there was a greater success rate for those who were fixating on the left dot than on the right dot. Overall success fixation was expressed as a ratio from 0 to 1 . Average rates and correlations for the eye tracking tasks are shown in Tables 17 and 18 for timepoints 1 and 2. All the remaining timepoints showed similar results and are not shown here. The next sets of plots are used to show the success fixation patterns over time (see Figures 8-27). A control and alcohol participant's raw fixation data and accuracy of response data are displayed. These plots show patterns over time, and are indicative of visuospatial attention. Eye movements are not perfect; using the Euclidean distance to compute overall success fixation for the eye tracking task shows that parallelprocessing occurred for the dual tasks. 
Figure 7. Euclidean distance formula used to measure accuracy for eye tracking task

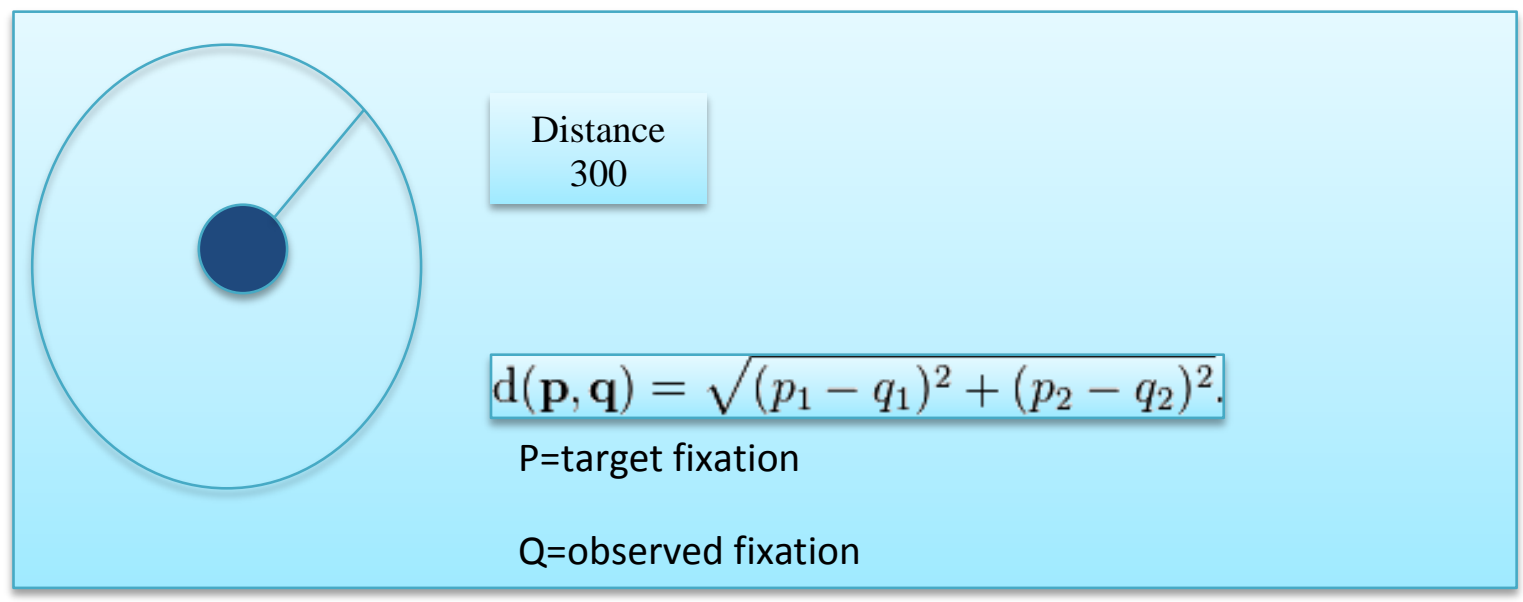

Table 16. Cumulative distribution of accuracy for the eye tracking task

\begin{tabular}{lrrrrrrrr}
\hline Minimum & $\begin{array}{r}\text { 10th } \\
\text { Pctl }\end{array}$ & $\begin{array}{r}\text { 25th } \\
\text { Pctl }\end{array}$ & Mean & Median & Std Dev & $\begin{array}{r}\text { 75th } \\
\text { Pctl }\end{array}$ & $\begin{array}{r}\text { 90th } \\
\text { Pctl }\end{array}$ & Maximum \\
\hline $\mathbf{1 . 0 0}$ & 116.47 & 242.22 & 336.94 & 319.58 & 184.67 & 407.54 & 530.70 & 1307.81 \\
\hline
\end{tabular}

TABLE 17. Summary Statistics and Correlation Matrix of Eye Tracking Tasks (Timepoint 1)

\begin{tabular}{lcccc}
\hline \multicolumn{5}{c}{ Simple Statistics of Eye Tracking Task (N=41) } \\
\hline Eye Tracking Task & Mean & Std Dev & Minimum & Maximum \\
\hline $\begin{array}{c}\text { 1. Success Fixation } \\
\quad \text { (overall) }\end{array}$ & 0.43 & 0.18 & 0.16 & 0.77 \\
$\begin{array}{c}\text { 2. Success Fixation } \\
\text { (center dot) }\end{array}$ & 0.50 & 0.18 & 0.20 & 0.81 \\
$\begin{array}{c}\text { 3. Success Fixation } \\
\quad \text { (left dot) }\end{array}$ & 0.32 & 0.23 & 0.01 & 0.83 \\
4. Success Fixation \\
(right dot)
\end{tabular}

Correlation Matrix of Eye Tracking Task $(\mathrm{N}=41)$

Eye Tracking Task

1

2

3

4 


\begin{tabular}{lllll}
\hline $\begin{array}{c}1 . \text { Success Fixation } \\
\text { (overall) }\end{array}$ & - & & \\
$\begin{array}{c}\text { 2. Success Fixation } \\
\quad \text { (center dot) }\end{array}$ & $0.99^{*}$ & - & \\
$\begin{array}{c}\text { 3. Success Fixation } \\
\quad \text { (left dot) }\end{array}$ & $0.96^{*}$ & $0.93^{*}$ & - \\
$\begin{array}{c}\text { 4. Success Fixation } \\
\text { (right dot) }\end{array}$ & $0.78^{*}$ & $0.72^{*}$ & $0.79^{*}$ & - \\
\hline
\end{tabular}

*All Correlations are significant at the <.0001 level (2-tailed).

TABLE 18. Summary Statistics and Correlation Matrix of Eye Tracking Tasks (Timepoint 2)

\begin{tabular}{lcccc}
\hline \multicolumn{5}{c}{ Simple Statistics of Eye Tracking Task (N=41) } \\
\hline Eye Tracking Task & Mean & Std Dev & Minimum & Maximum \\
\hline $\begin{array}{c}\text { 1. Success Fixation } \\
\text { (overall) }\end{array}$ & 0.42 & 0.19 & 0.17 & 0.77 \\
$\begin{array}{c}\text { 2. Success Fixation } \\
\text { (center dot) }\end{array}$ & 0.49 & 0.20 & 0.21 & 0.82 \\
$\begin{array}{c}\text { 3. Success Fixation } \\
\text { (left dot) }\end{array}$ & 0.31 & 0.23 & 0.01 & 0.87 \\
4. Success Fixation \\
(right dot)
\end{tabular}

Correlation Matrix of Eye Tracking Task $(\mathrm{N}=41)$

\begin{tabular}{|c|c|c|c|c|}
\hline Eye Tracking Task & 1 & 2 & 3 & 4 \\
\hline $\begin{array}{l}\text { 1. Success Fixation } \\
\text { (overall) }\end{array}$ & 一 & & & \\
\hline $\begin{array}{l}\text { 2. Success Fixation } \\
\text { (center dot) }\end{array}$ & $1.00 *$ & - & & \\
\hline $\begin{array}{l}\text { 3. Success Fixation } \\
\text { (left dot) }\end{array}$ & $0.98 *$ & $0.96^{*}$ & - & \\
\hline $\begin{array}{l}\text { 4. Success Fixation } \\
\text { (right dot) }\end{array}$ & $0.79 *$ & $0.73^{*}$ & $0.83^{*}$ & - \\
\hline
\end{tabular}

*All Correlations are significant at the <.0001 level (2-tailed). 


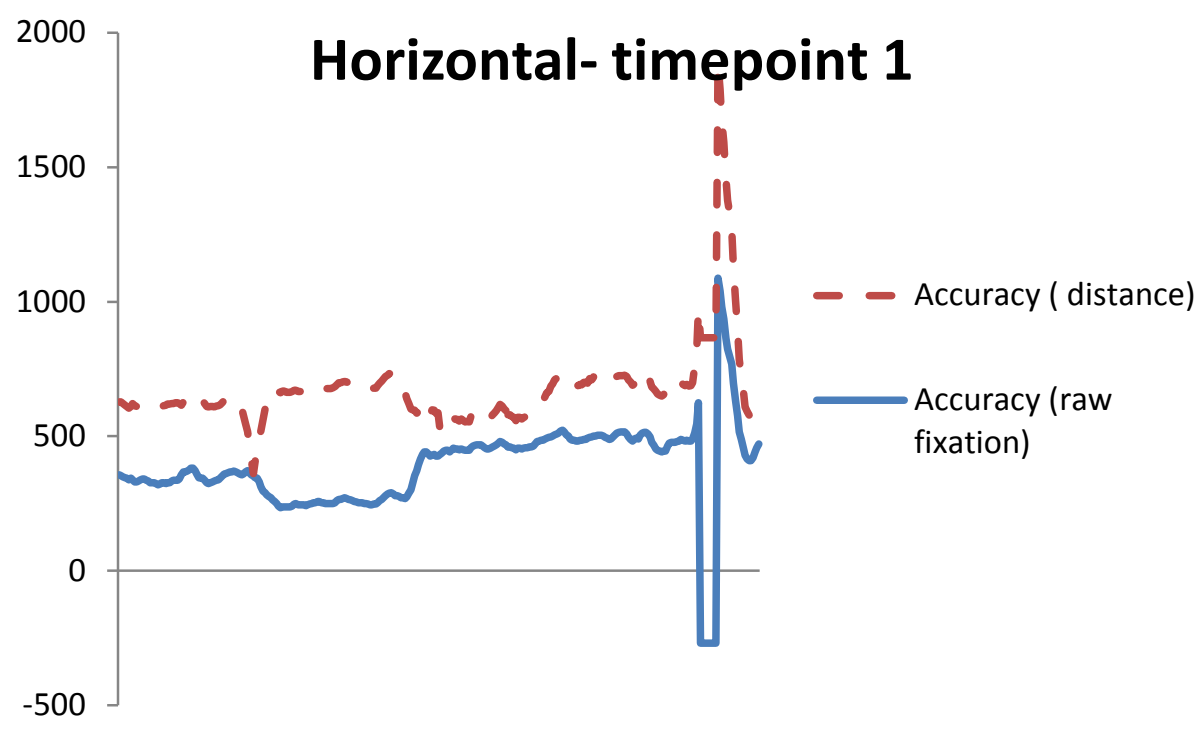

\section{Vertical - Timepoint 1}

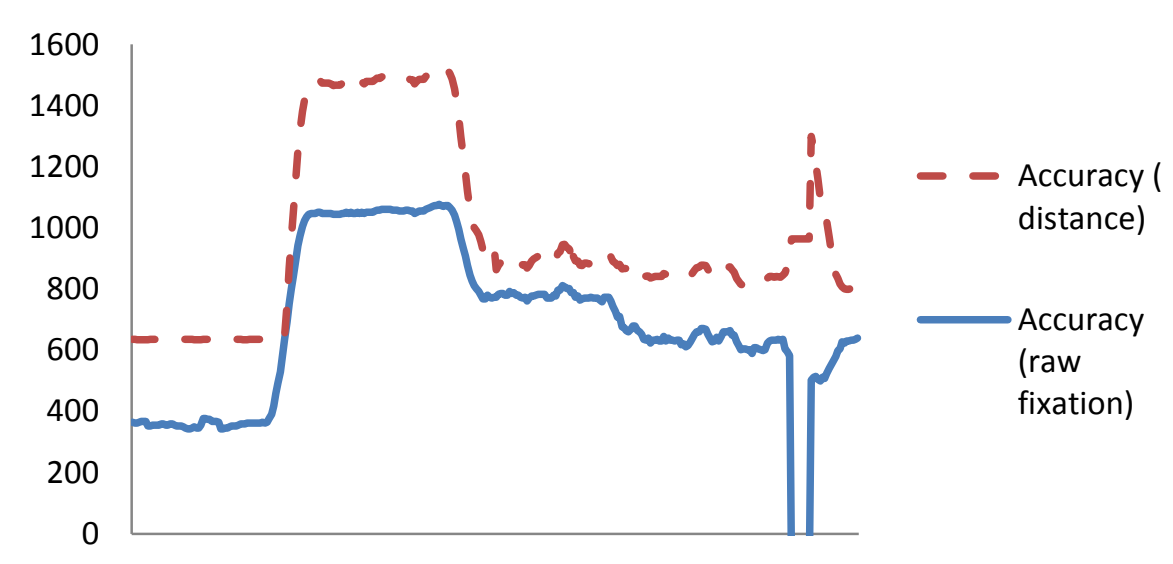

Figures 8-9. Control participant vertical and horizontal accuracy plots for timepoint 1 

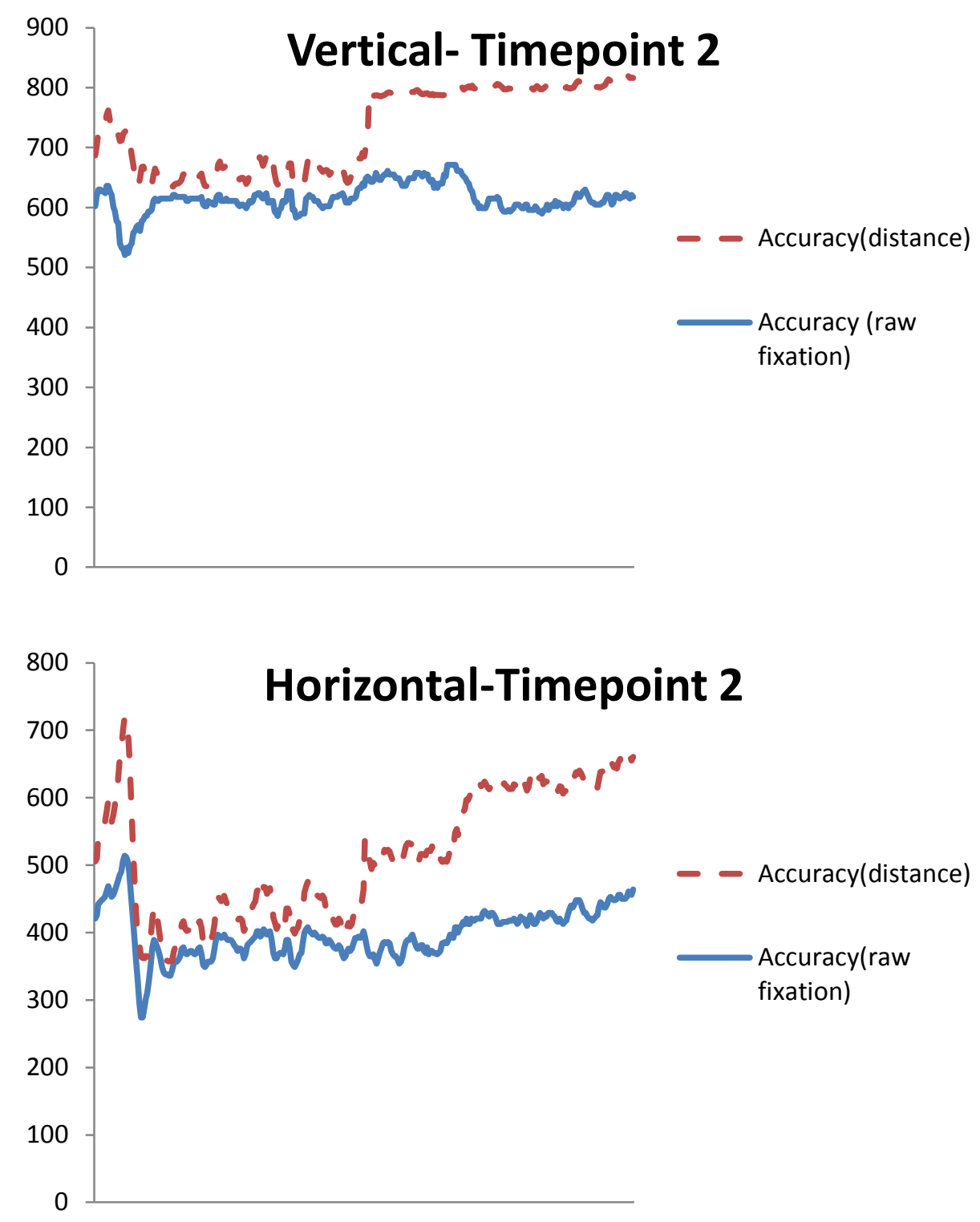

Figures 10-11. Control participant vertical and horizontal accuracy plots for timepoint 2 

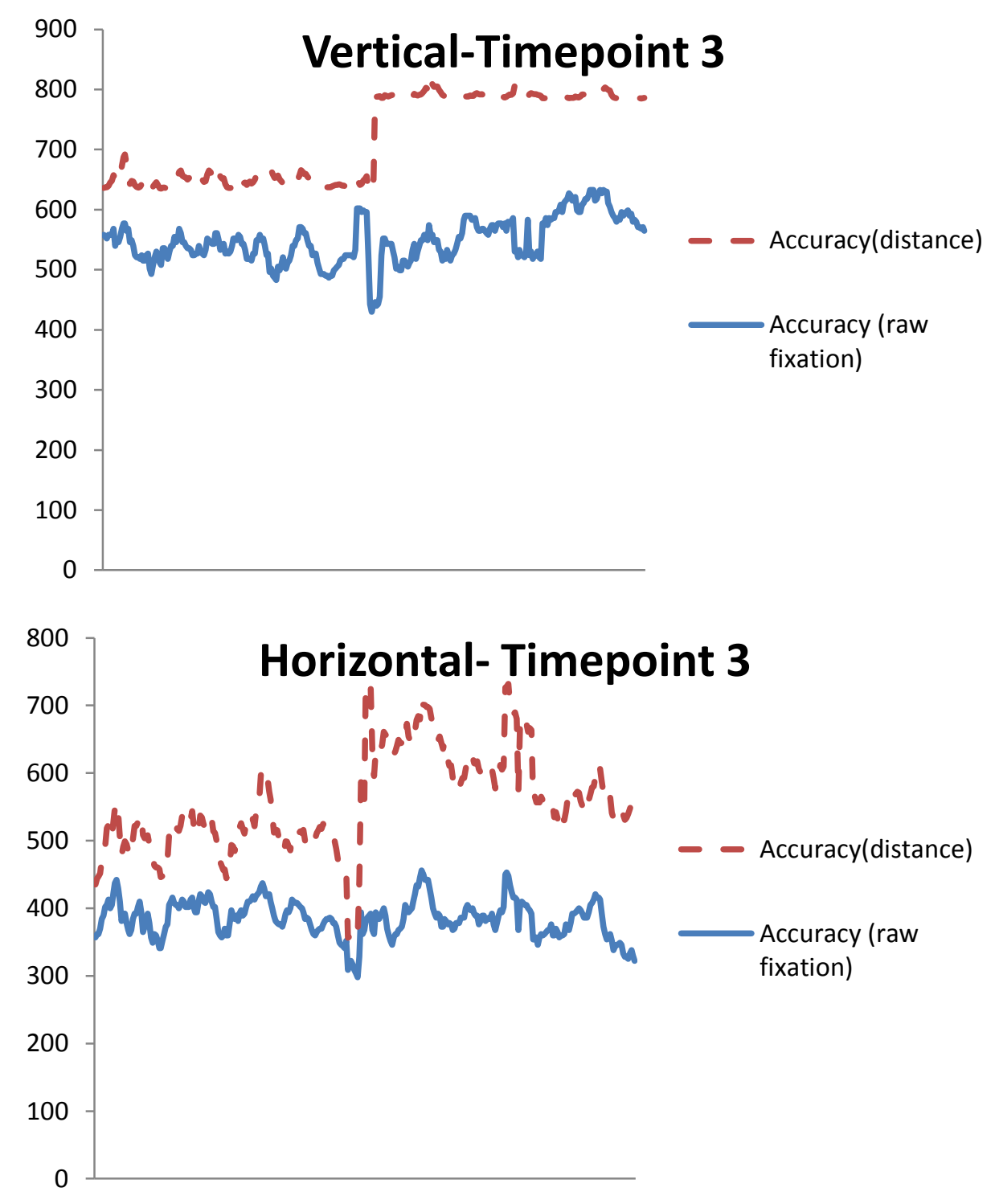

Figures 12-13. Control participant vertical and horizontal accuracy plots for timepoint 3 

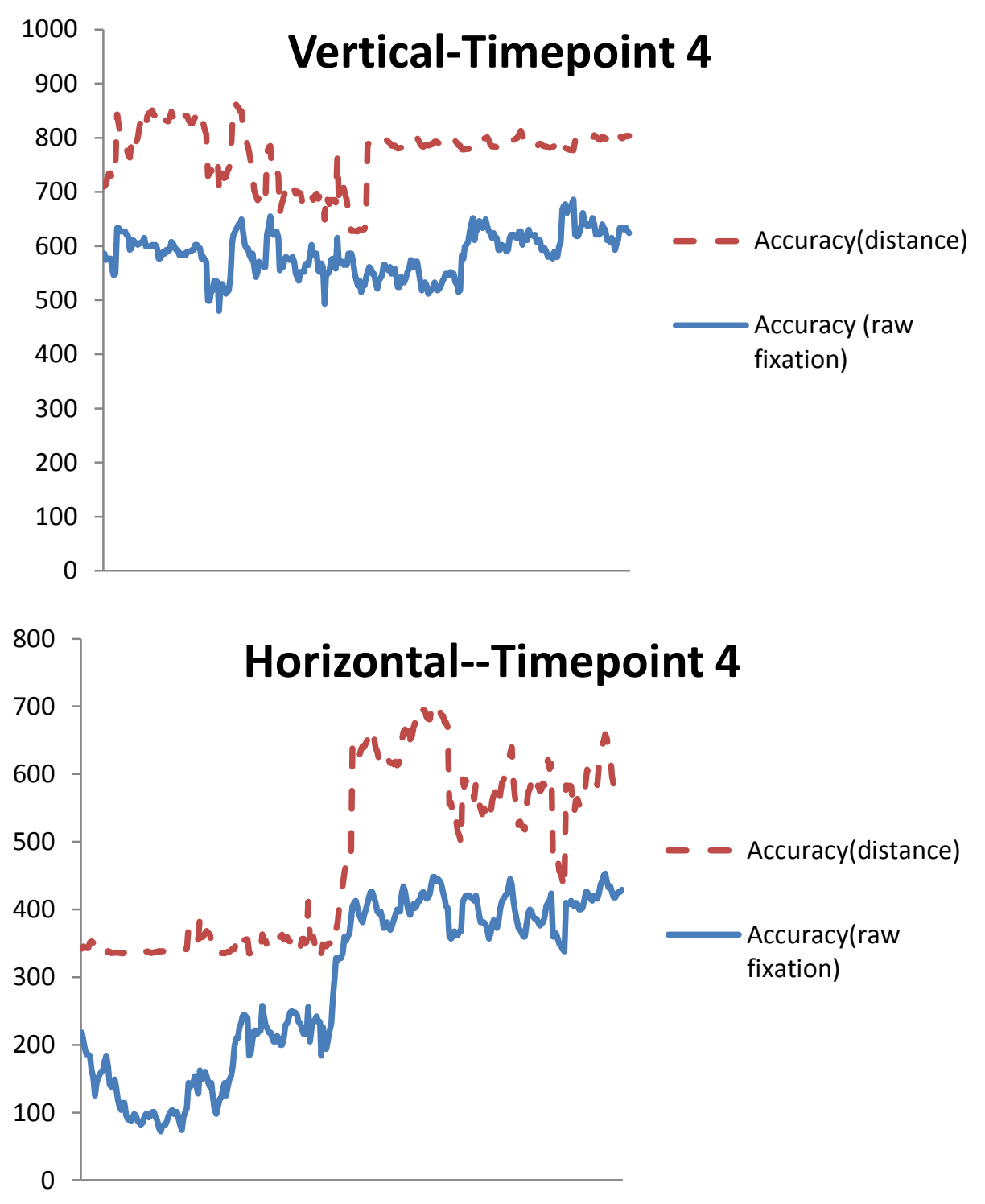

Figures 14-15. Control participant vertical and horizontal accuracy plots for timepoint 4 

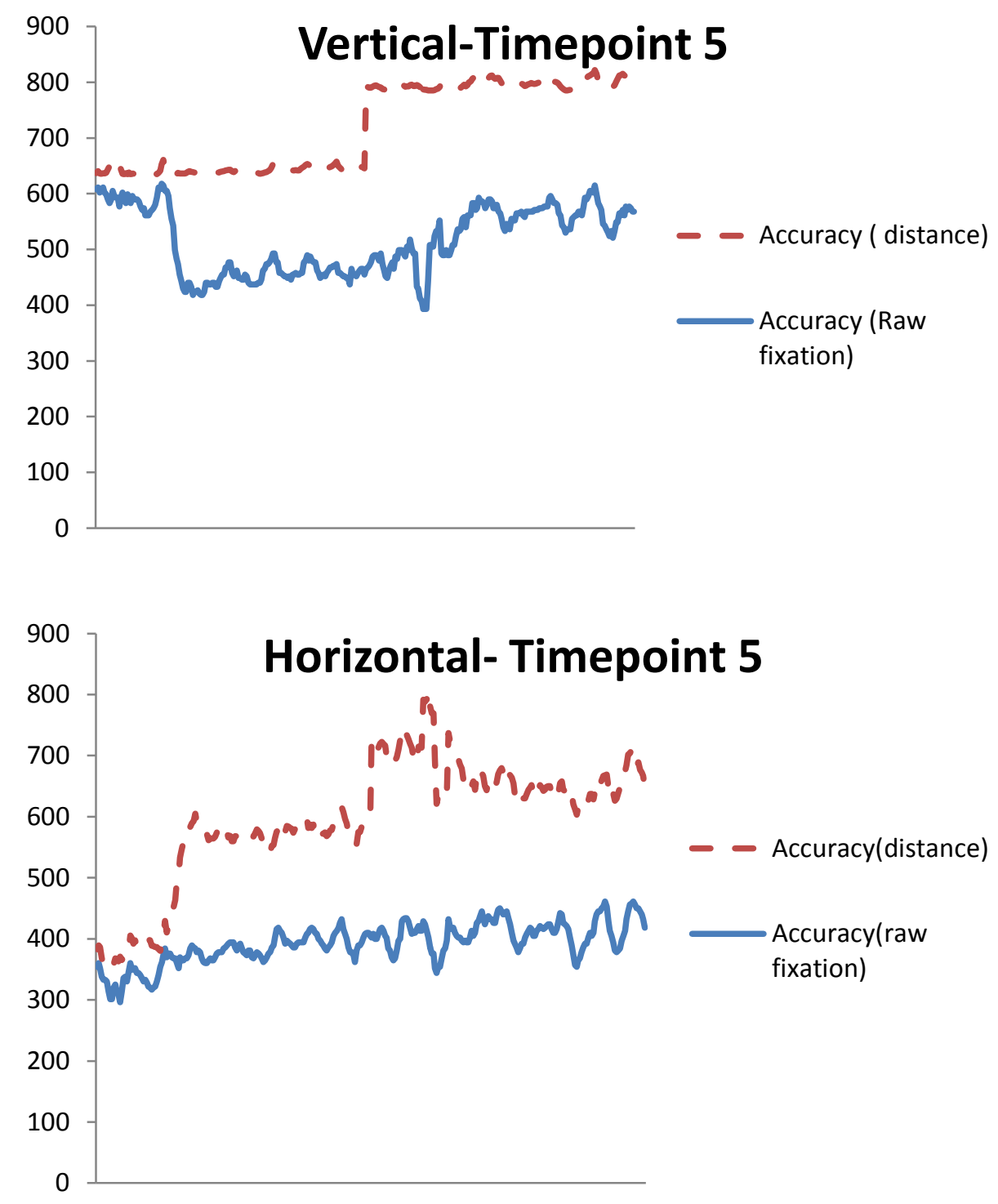

Figures 16-17. Control participant vertical and horizontal accuracy plots for timepoint 5 

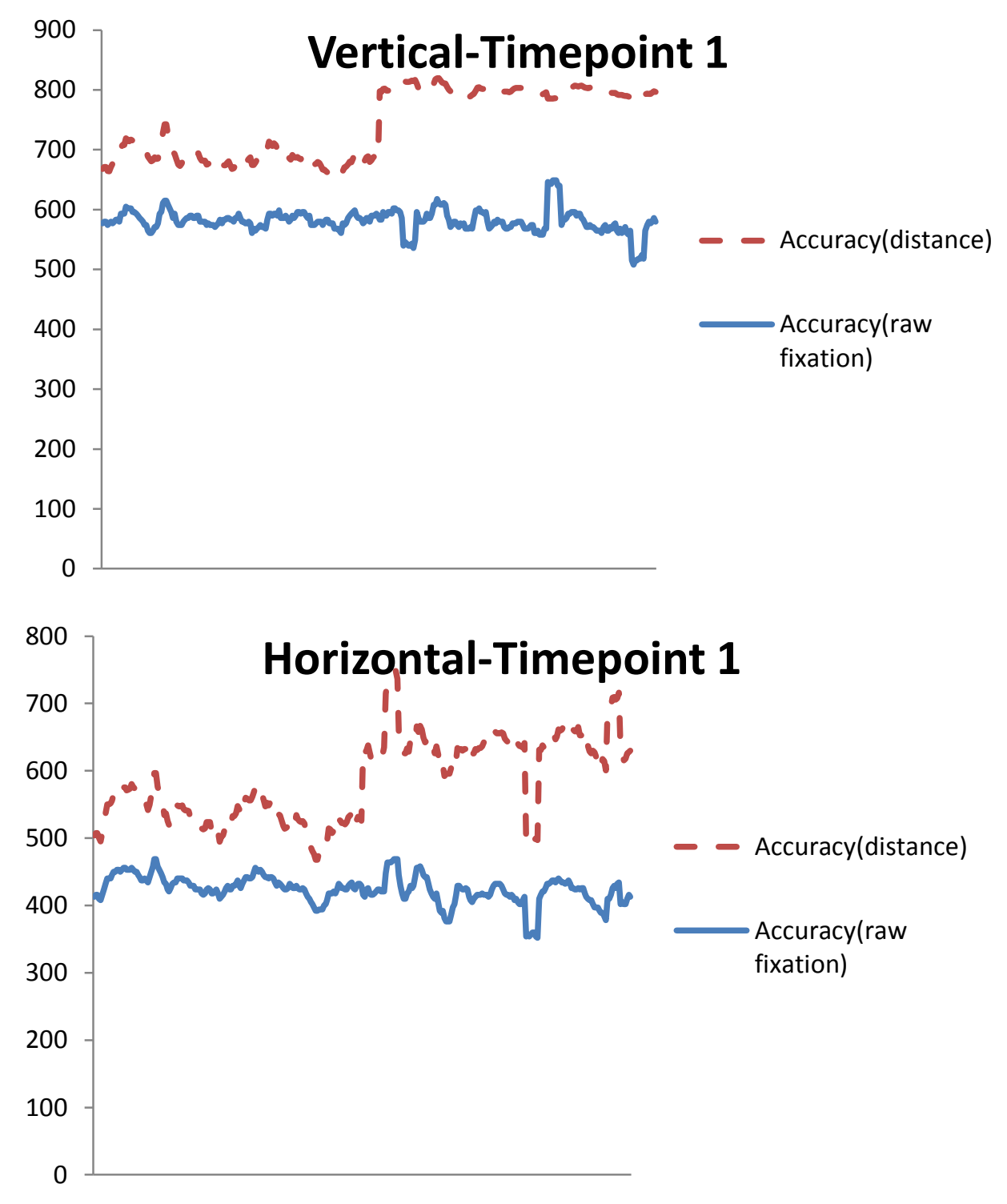

Figures 18-19. Alcohol participant vertical and horizontal accuracy plots for timepoint 1 

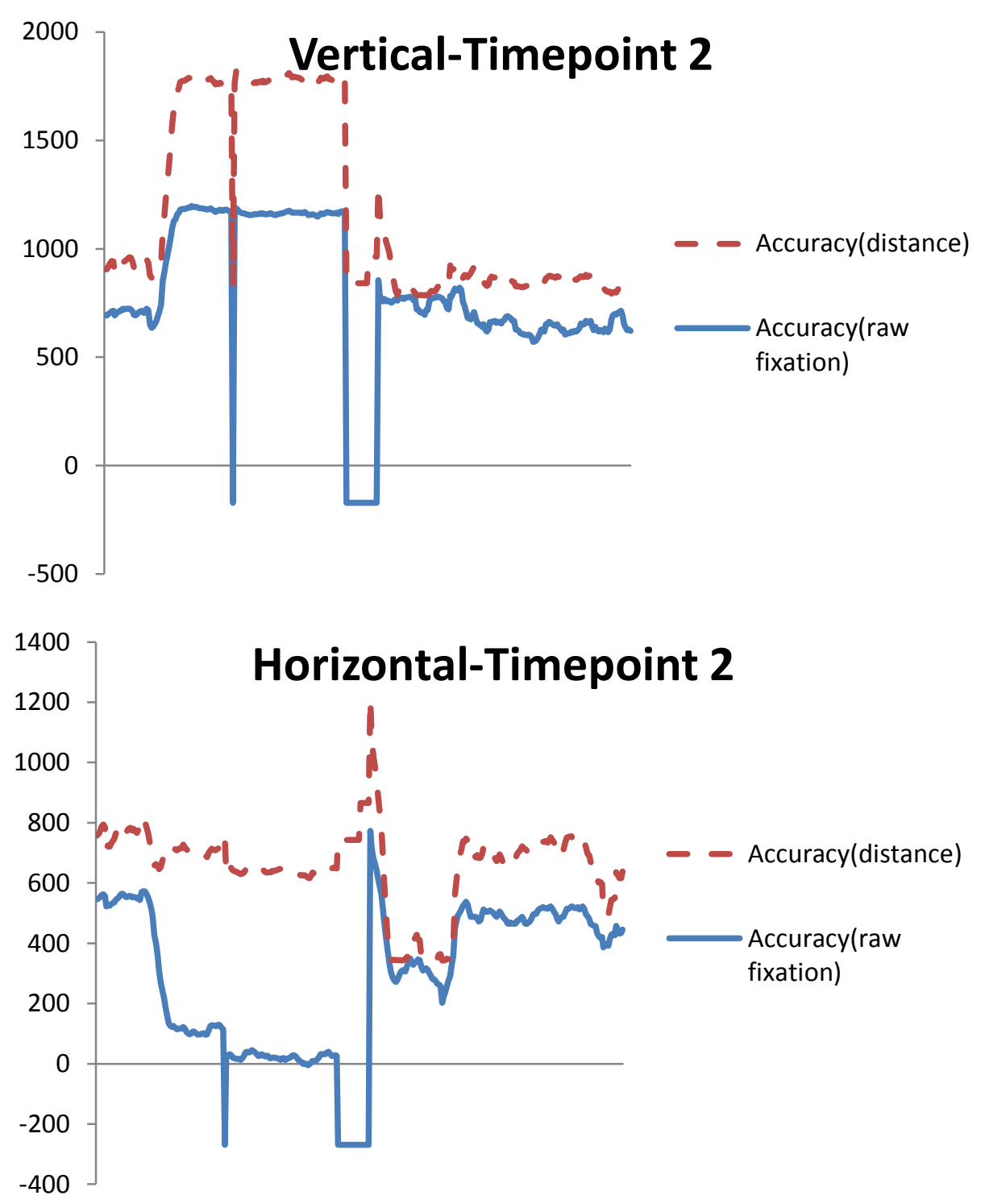

Figures 20-21. Alcohol participant vertical and horizontal accuracy plots for timepoint 2 

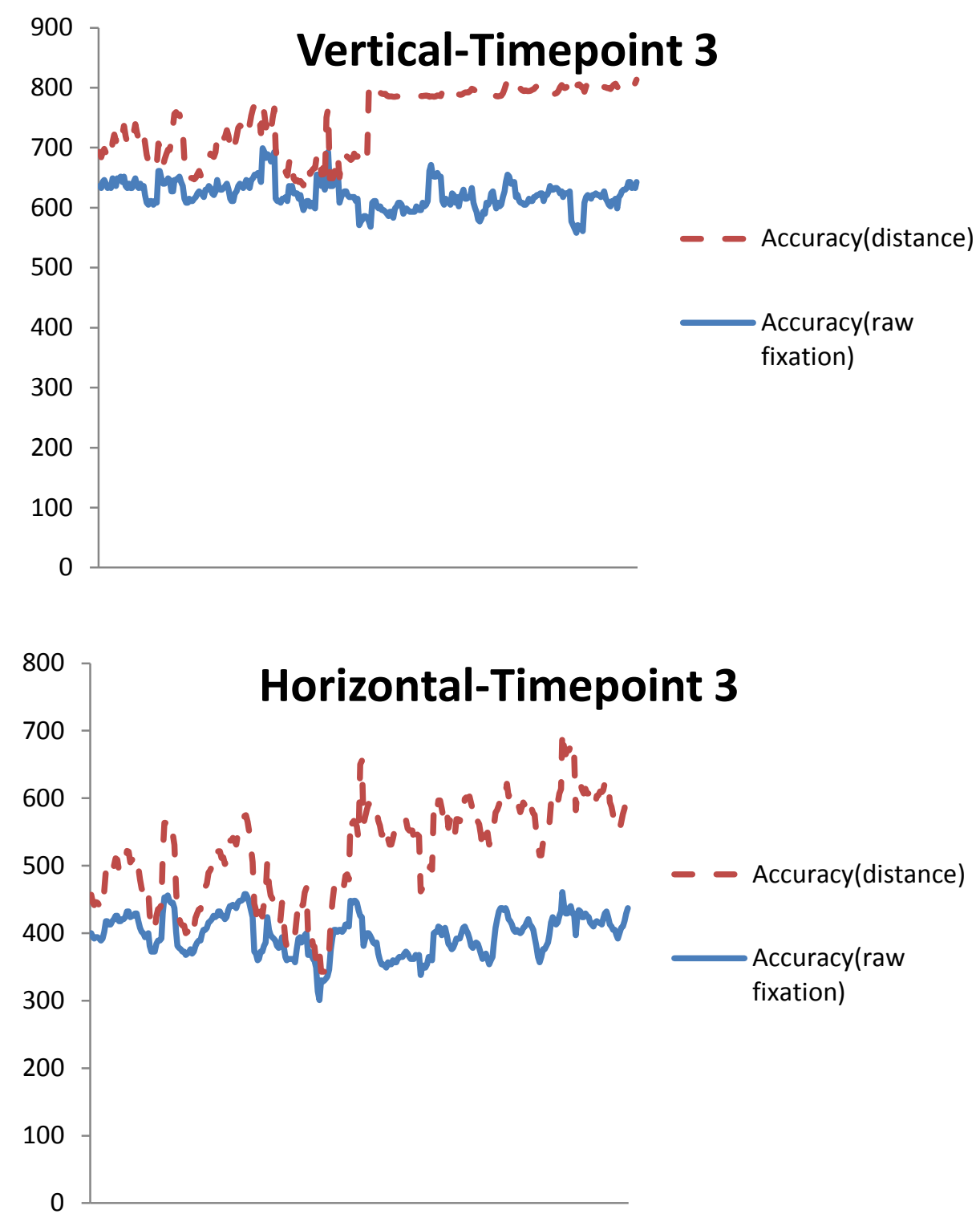

Figures 22-23. Alcohol participant vertical and horizontal accuracy plots for timepoint 3 

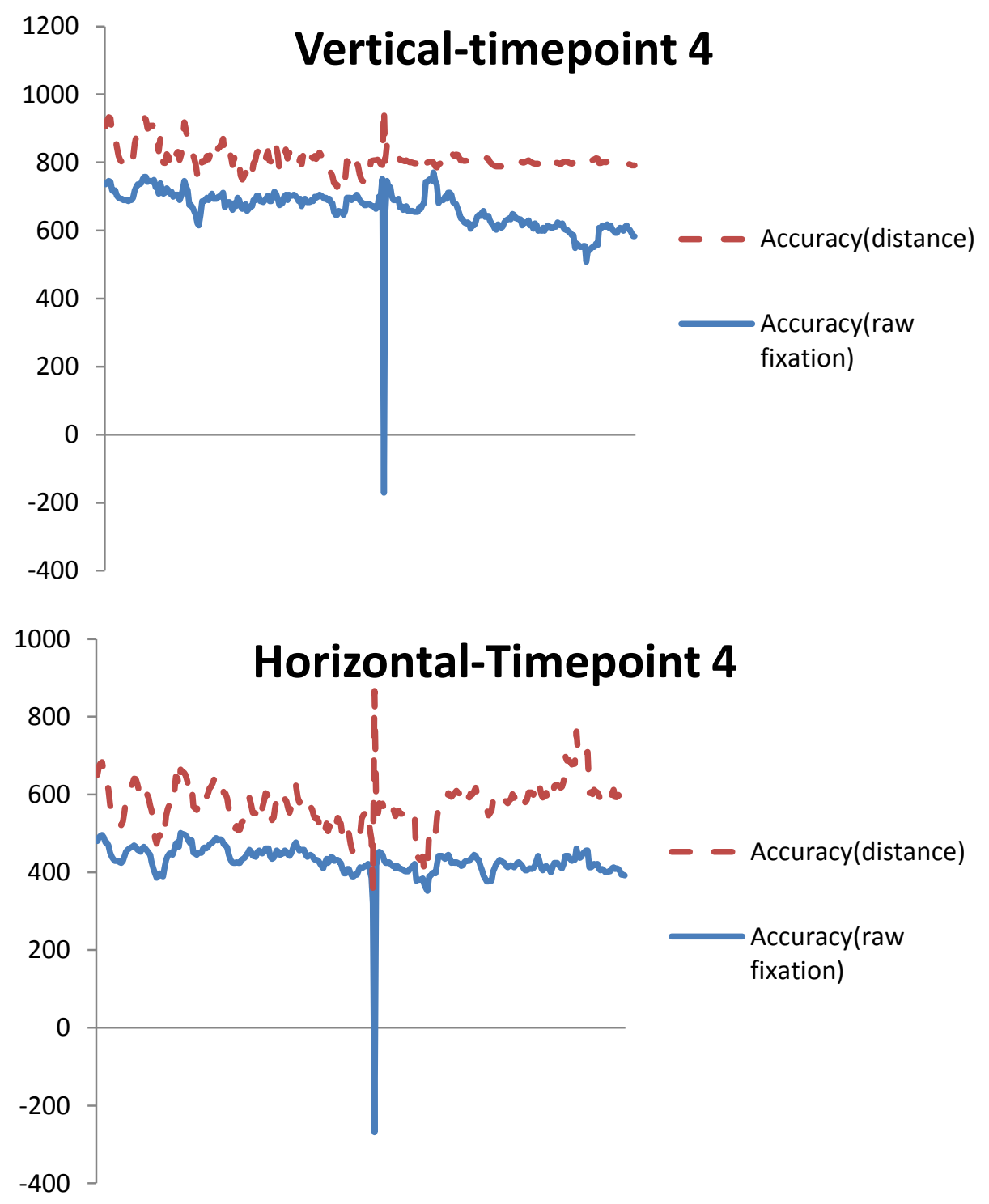

Figures 24-25. Alcohol participant vertical and horizontal accuracy plots for timepoint 4 

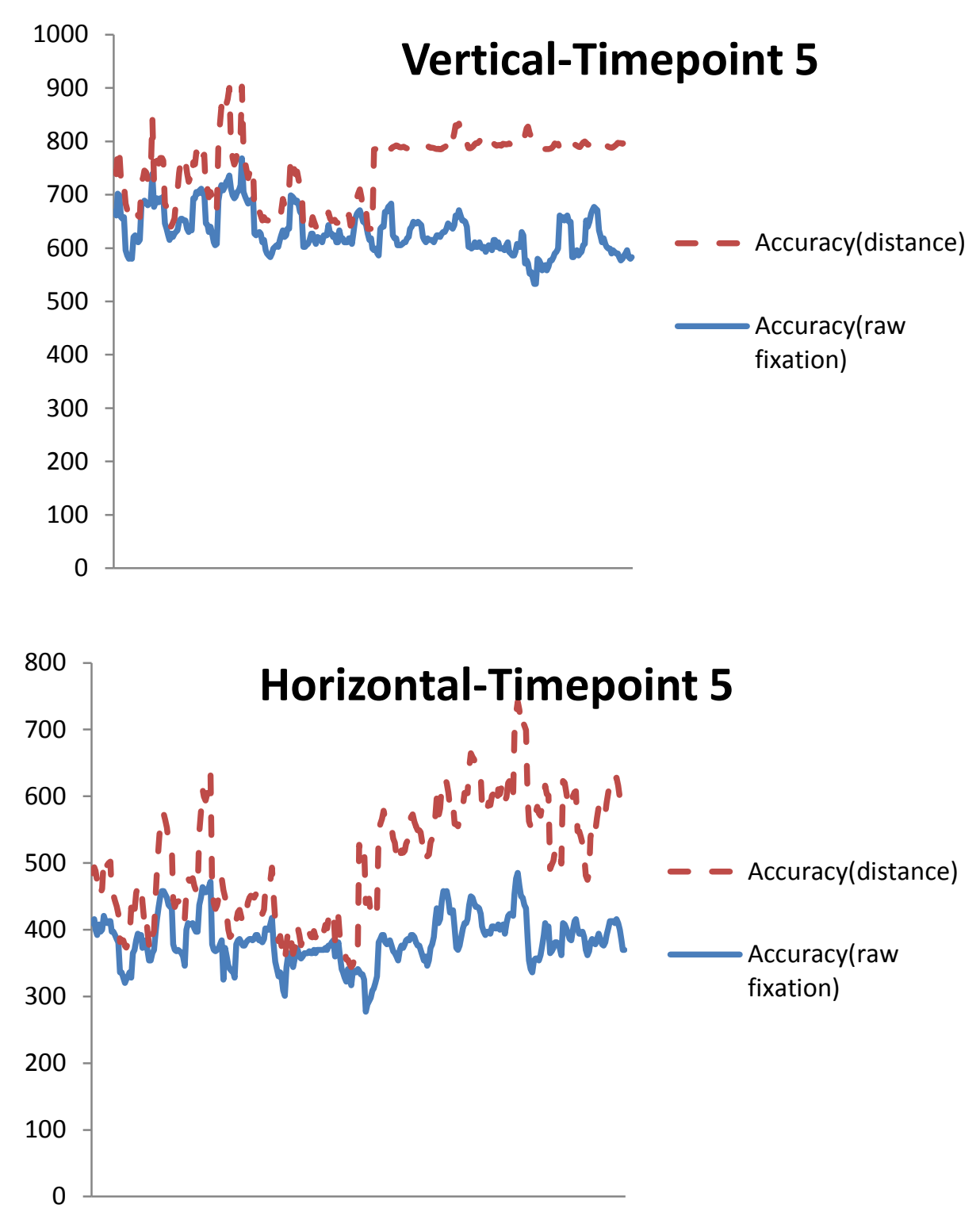

Figures 26-27. Alcohol participant vertical and horizontal accuracy plots for timepoint 5

Tradeoff plots (Figures 28-31) are used to show the relationship between eye tracking and recognition performance under different attentional instructions. Attention was manipulated by prioritizing one task or the other using instructions. A tradeoff would appear as a negatively-sloping line on the graph. The point representing performance on the two tasks under the eye tracking priority condition is labeled with an 'E'. The point representing performance on the two tasks under the recognition priority 
condition is labeled with an ' $\mathrm{R}$ '. Evaluating the outcome performance at Timepoint 2, there appears to be a distinct instruction effect horizontally, with the $\mathrm{R}$ points consistently to the right of the E points. When the recognition task was prioritized, there was a shift toward higher performance on that task, but with no change in the eye tracking reaction time and little effect of alcohol.

At time points 3 and 5, negative sloping lines (tradeoff between performances on the two tasks) and impairment due to alcohol (alcohol line lower and/or to the left of the placebo line) were found. However, a more severe tradeoff between the tasks under alcohol is not present; this would have been shown if the length of the alcohol tradeoff line was greater than the length of the placebo tradeoff line. At time points 2 and 4 the instructional effect is present, but eye tracking performance is fairly constant, and does not trade off with recognition as expected. At time point 4, there may be a small alcohol effect on eye tracking only. 


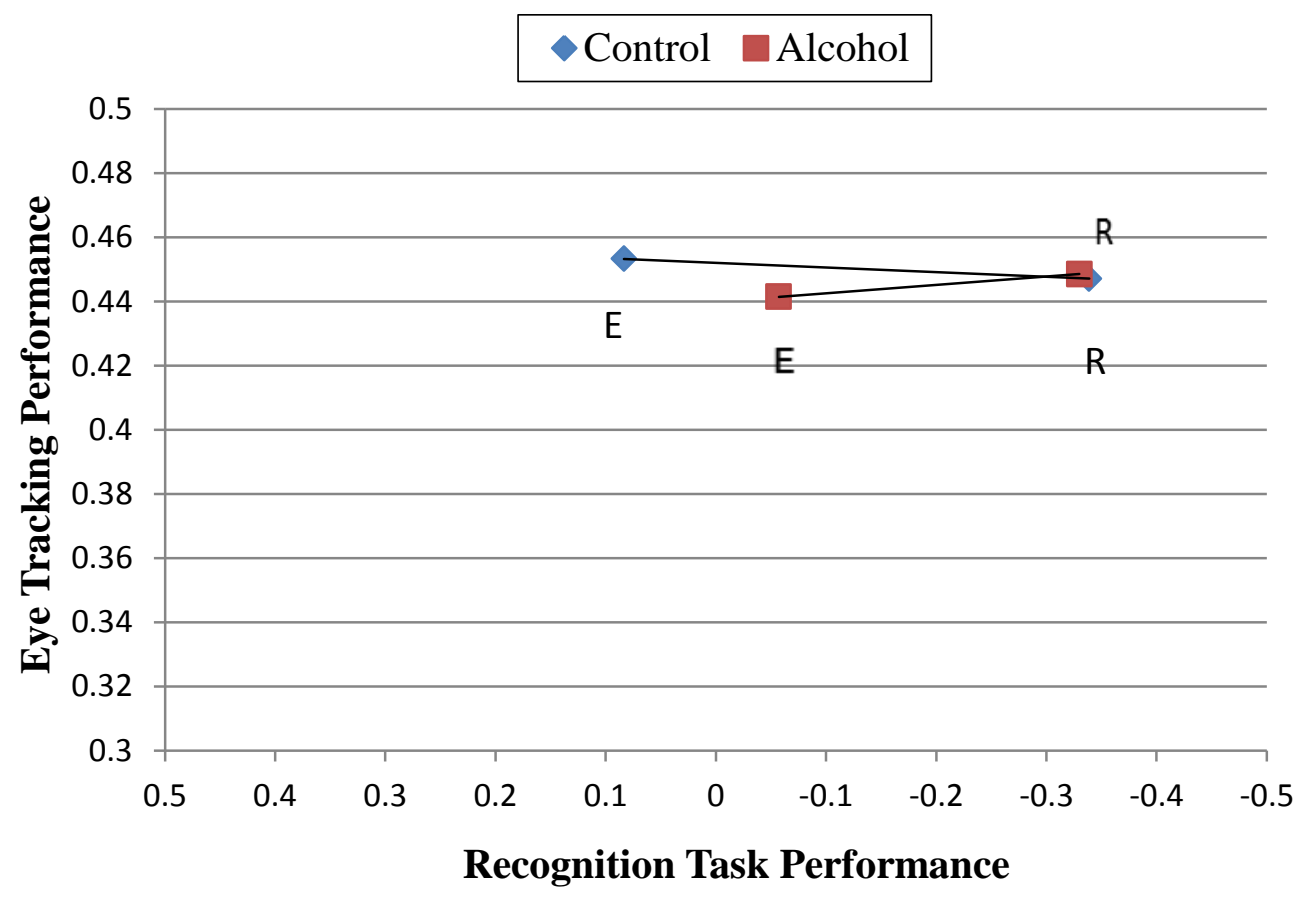

Figure 28. Timepoint 2 of the dual tasks

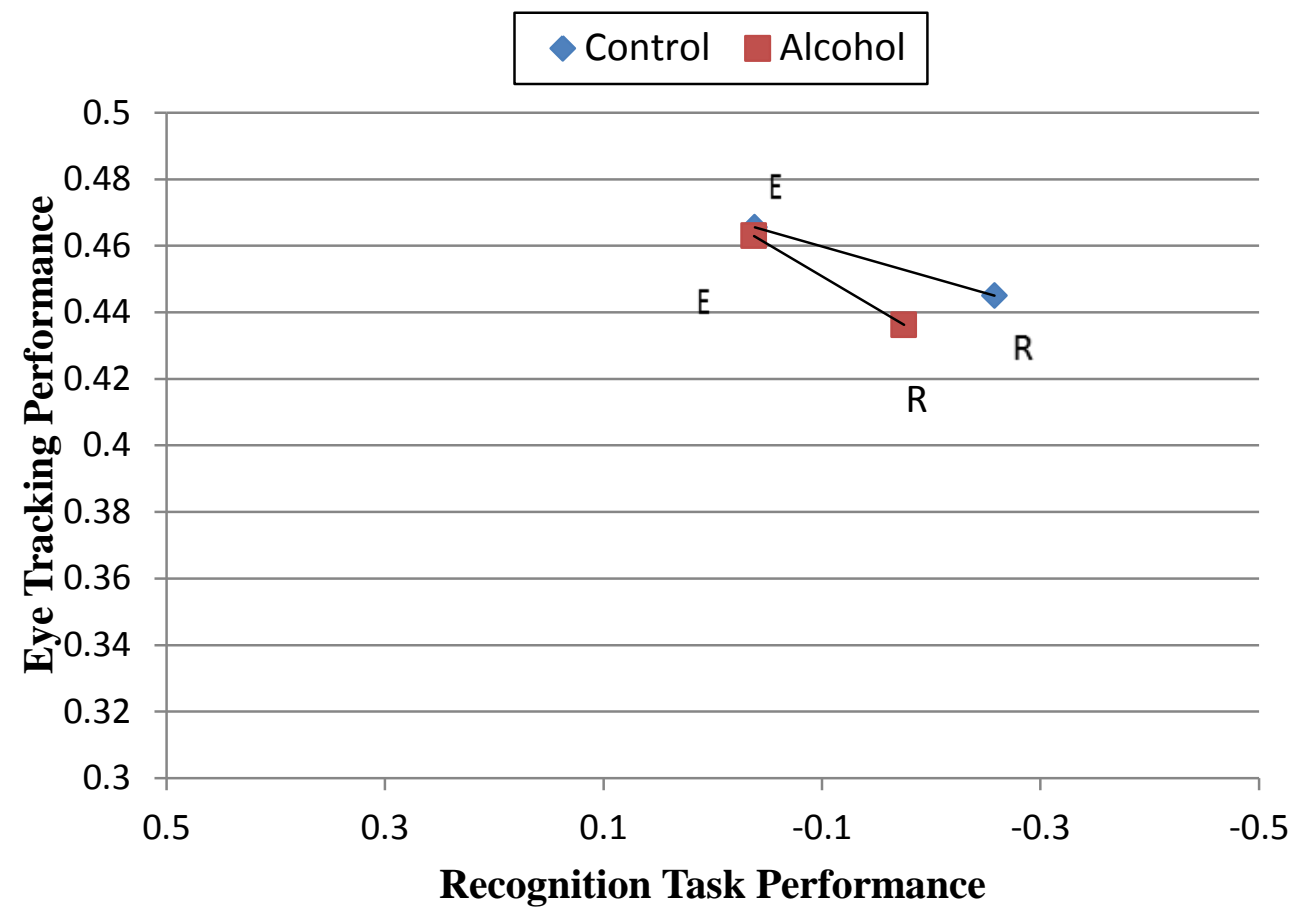

Figure 29. Timepoint 3 of the dual tasks 
Timepoint 3 or the peak timepoint showed slight improvement in the success fixation task for both groups. When the recognition task was prioritized, the control group performed better than the alcohol group. The control group also did slightly better on the secondary task of eye fixation.

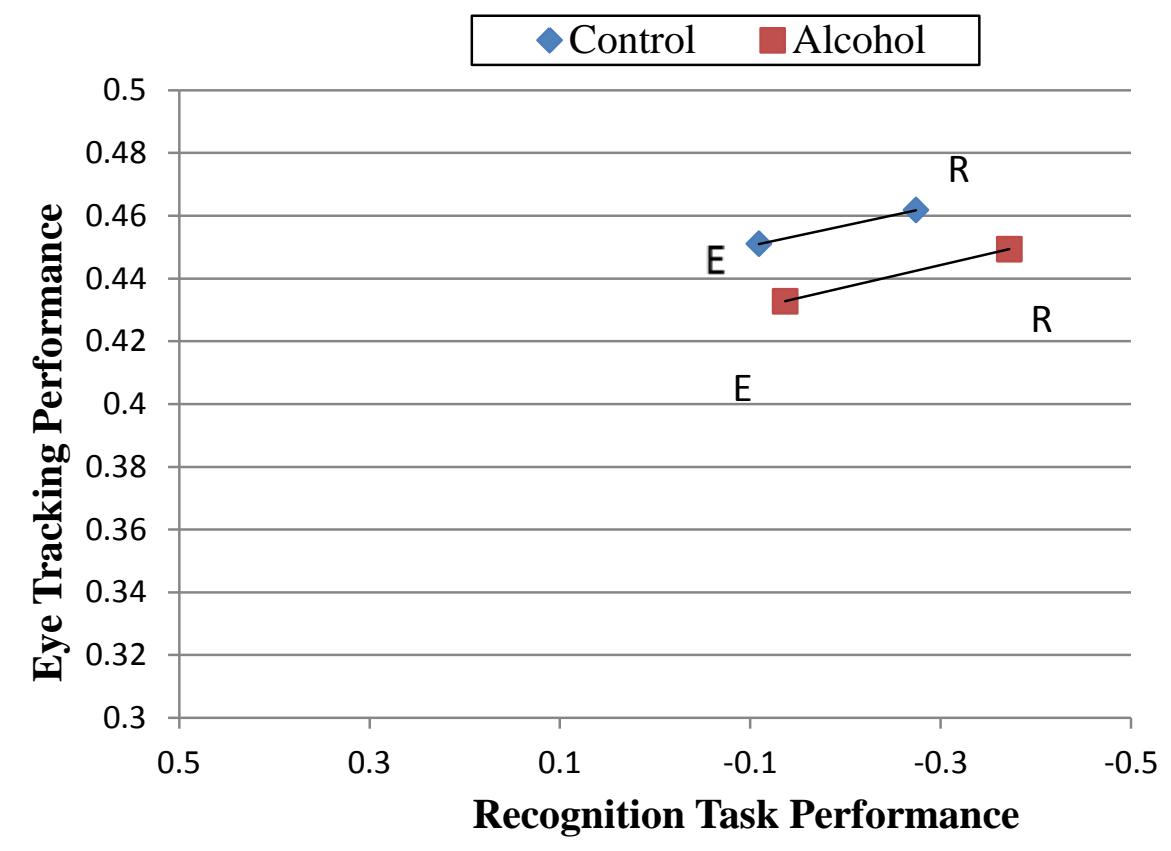

Figure 30. Timepoint 4 of the dual tasks

The conditional effect is still seen through timepoint 4. The control group performed better on the prioritized task of eye fixation. However, the alcohol group performed better on the recognition task in both of the conditions. 


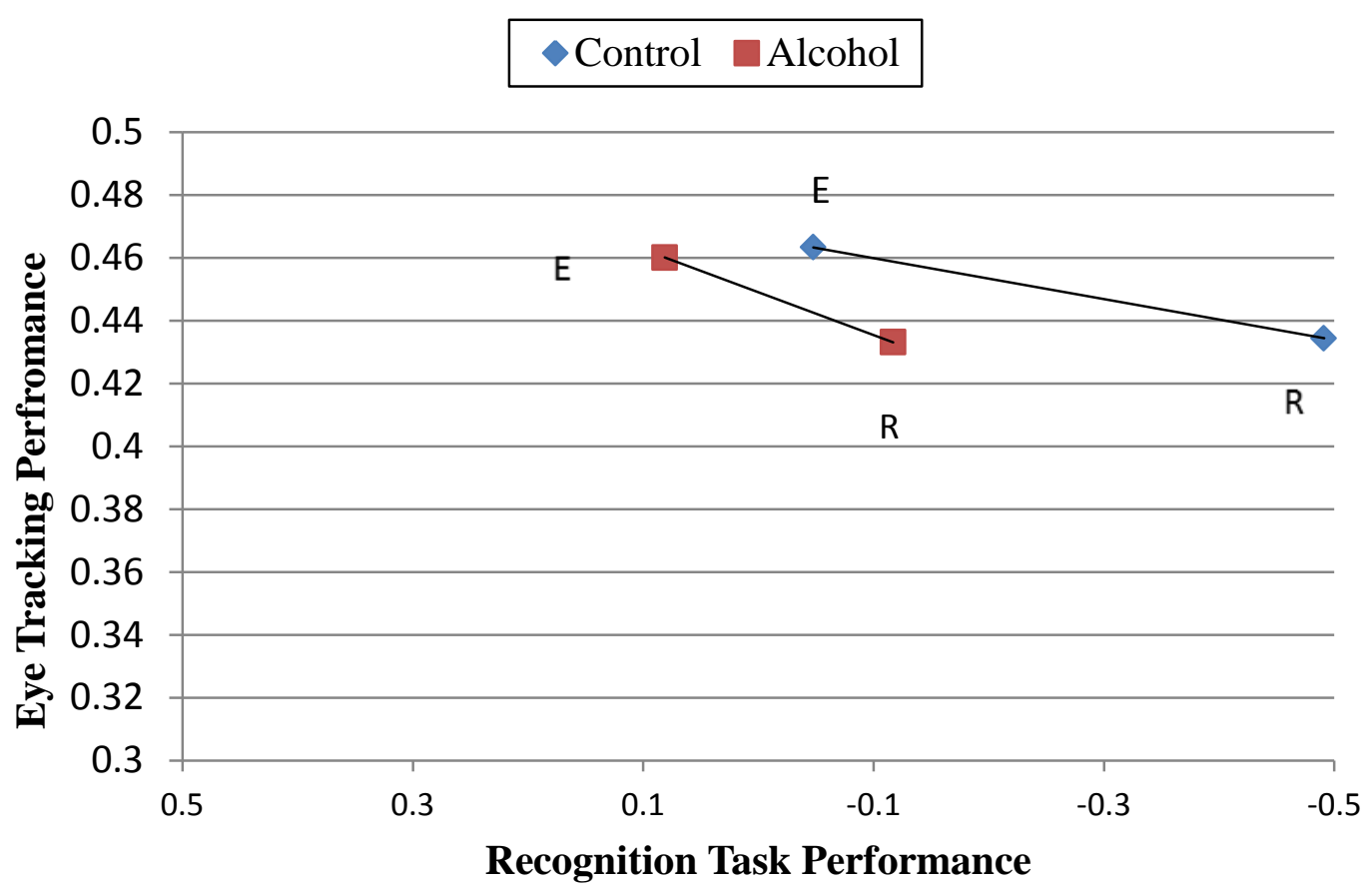

Figure 31. Timepoint 5 of the dual tasks

By the last timepoint, the dose response, although almost constant across the timepoints, is approaching the declining phase of the alcohol curve. Again, there seems to be no difference between the two groups when the success fixation task is prioritized. However, there are considerable gains made by the control group when the recognition task is prioritized. The alcohol group has a significant increase in their response time, although their success fixation is still at a rate similar to the control group. 


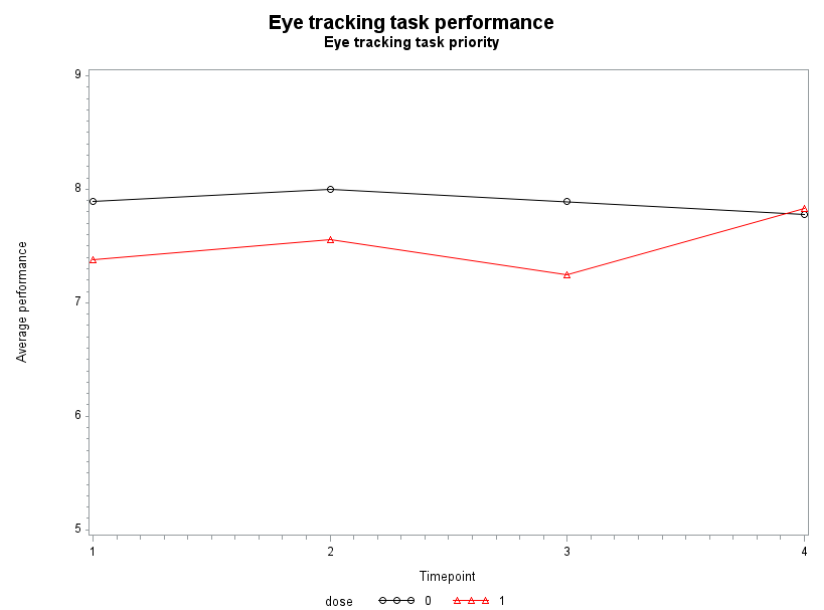

Eye tracking task performance

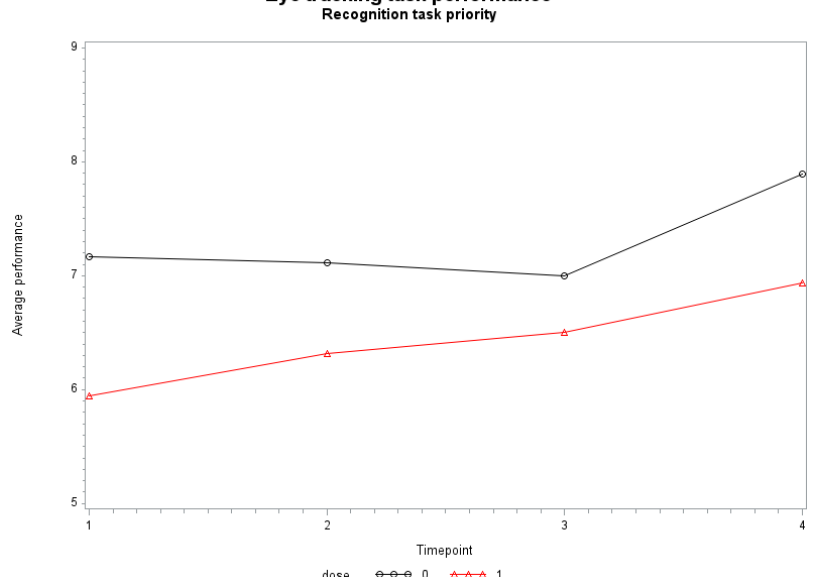

Light recognition task performance Eye tracking task priority

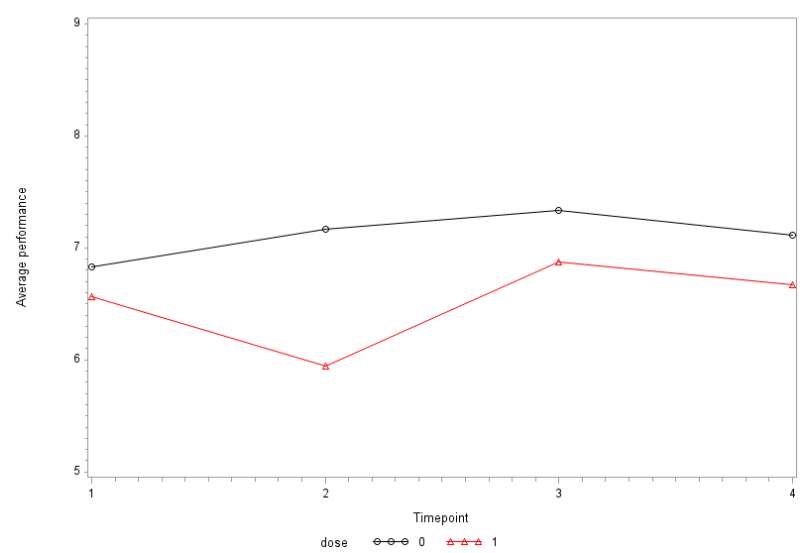



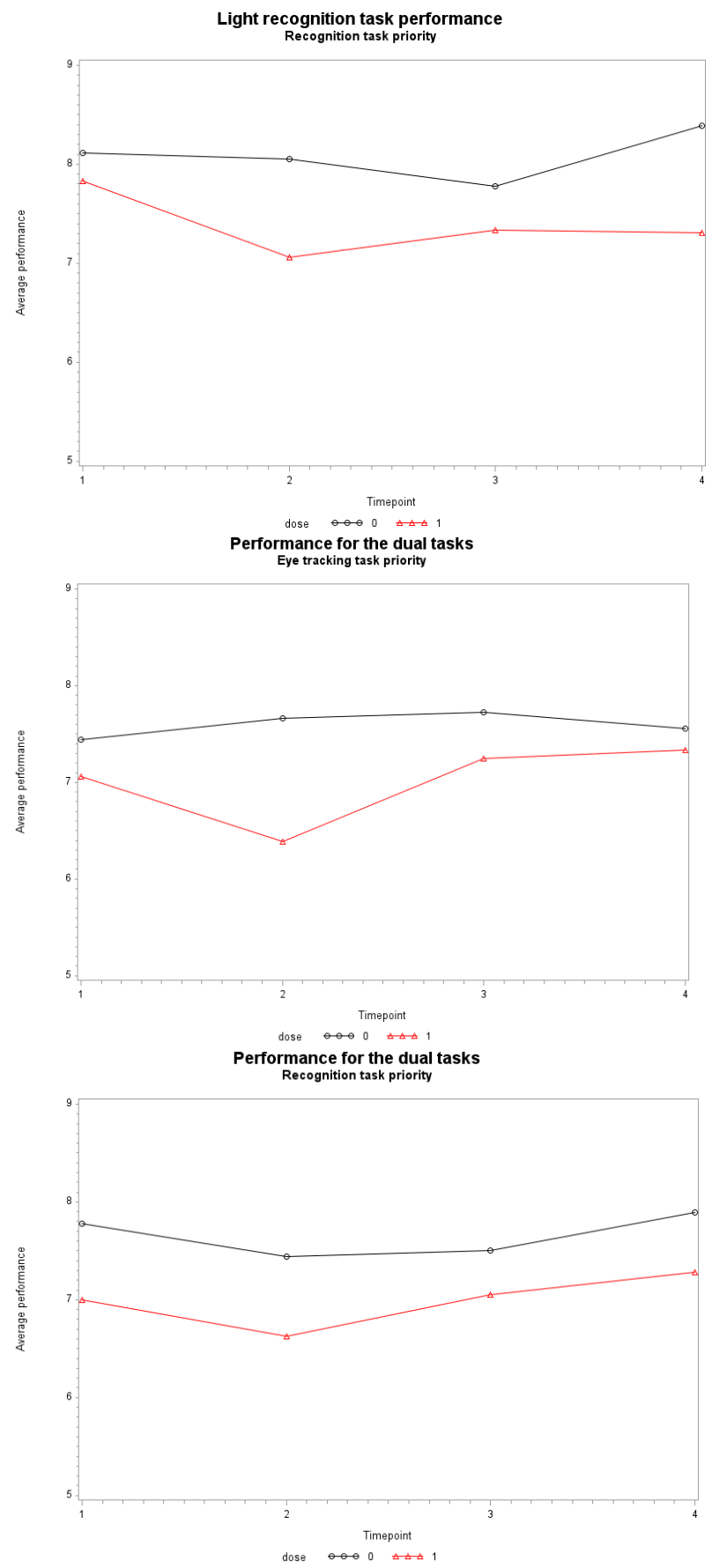

Figures 32-38. Self-report of performance for the dual tasks and individual tasks across the timepoints.

Brumback et al., 2007 showed that there was no difference in actual or self-rated performance impairment in a pegboard and Digit Symbol Substitution Task (DSST) in 
those participants who solely received alcohol versus those who did not. Although the participant was aware of both tasks throughout the various time points, instructions were used to manipulate the participant's attention to one task versus the other. The performance ratings were used to validate how well the participant felt he did throughout this manipulation. After each session, participants were asked to rate how well they thought they performed on a scale from 1 (not well) to 10 (extremely well). They were asked to rate how well they thought they performed on the dual tasks and then on the eye tracking task and the light recognition task. There were no significant differences between the two groups (see Figures 32-38).

Participants were asked to report how well they thought they performed on the dual tasks and how well they performed on each of the tasks alone. The instructional effect was always found to vary significantly with time for reaction time, forthe eye tracking priority condition, $(\mathrm{M}=529.7$ m.s., $\mathrm{SD}=132 \mathrm{~m} . \mathrm{s}$.$) and for, the light recognition$ priority condition, $(\mathrm{M}=449.3, \mathrm{SD}=126.8 \mathrm{~m} . \mathrm{s}),. \mathrm{F}(1,196)=15.35, \mathrm{p}=.0001$; however; the dose by time interaction effect was not always found. To control for BAC variation, alcohol dose was centered across the timepoints, the difference between each individual's BAC and the grand mean was used for each timpoint. the instructional effect was found for choice reaction time. Timepoints 4 and 5 differed; the alcohol group performed worse even with the recognition task priority. The centering of the BAC controlled for the variation in the alcohol dose.

The tradeoffs provide a comparative approach toeye fixation, or the ratio closest to fixating on the target, and choice reaction time. Instructional condition significantly affected choice reaction time. This is a common finding in the literature (Posner, 1980; 
Rizollati et al., 1987; Carassco et al., 2004). The orienting of attention to the response lights was reflected in a change in the participants' response time. The eye fixation success measure however stayed the same. Alcohol further inhibited this process; timepoint 3 showed a significant decrease in response time even with the recognition priority and success fixation remained the same between the two groups.

Dual task performance paradigms have been used in experiments for a long time and in different disciplines. Studies have used various types of measures and tasks to explore switching in attention and workload (e.g. Sperling \& Melchner, 1978). Visual attention and reaction time were used to study alcohol's effects on attention; accuracy and response time are useful metrics for studying attention. Although the main dependent variables for this study were composed of the eye tracking and reaction time data, other dependent variables are necessary to explore why alcohol effects may not be directly involved with attention. These other dependent variables include the BAES, or the biphasic alcohol effects scale, which is used to test for both sedating and stimulating effects of alcohol. Although this study mostly occurred on the ascending phase of the alcohol curve, these effects are known to vary across individuals and can be predictive of alcohol expectancy.

BAES subscales, which measured the sedating and stimulating effects of alcohol on subject participants, are more affected by alcohol expectations than by actual alcohol consumption. All correlations were small and insignificant; no group differences were observed in the overall subjective response for either sedation or stimulation across time (see Figures 39-40). 
The Alcohol Expectancy Questionnaire (AEQ) and the Cognitive Failures Questionnaire (CFQ) are used to predict the participant's perception of the effects of alcohol. These questionnaires were given to participants in this study at baseline. The AEQ has 6 subfactors that are a reliable assessment of the participant's perception of alcohol effects. Factor 1 contains items that define alcohol as a global and positive agent; factor 2 contains items about expectations that alcohol will enhance both social and physical pleasure; factor 3 contains items about sexual enhancement and performance; factor 4 items are more related to arousal and power and aggression; factor 5 items are about increased social assertiveness, and factor 6 items are about relaxation/tension reduction. Results showed that there were no differences between the alcohol and placebogroups on any of the 6 factors. An association between alcohol-related problems and positive expectancies such as arousal expectancies was found. Arousal is usually indicative of heavy drinkers.

The Drinking Expectancy Questionnaire (DEQ) was used to show the ratio of participants who thought they received alcohol and actually did, versus those who did not receive alcohol and thought they did not. This questionnaire is a valid indicator of placebo effects in alcohol studies, and how expectations can be highly predictive of behavior. In this study, the DEQ was a good indicator of how well the participants thought they performed on the overall tasks and how many drinks they had consumed. These results are plotted in figures 41-48. The alcohol group is labeled a s ' 1 ' and the placebo group is labeled as ' 0 ' for all the figures.

Acute tolerance has implications for driving performance. Those who are more likely to drink and drive tend to underestimate self-intoxication levels and may be less 
aware of their affective state under the influence of alcohol. Visual attention and motor response are also affected by alcohol over time. The decline in behavioral function as well as in subjective affective response is important in describing the overall effects of alcohol consumption in a college sample. Also, acute tolerance to the subjective effects of alcohol is important in performance.
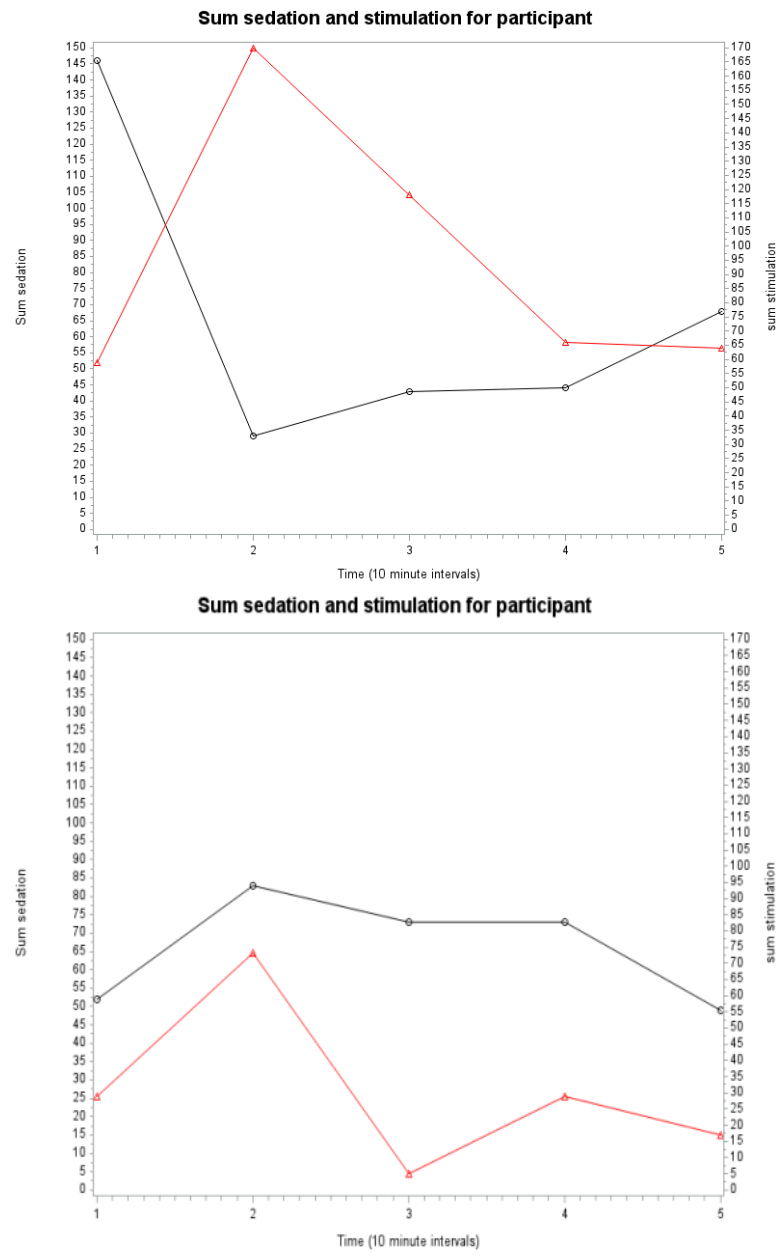

Figures 39-40. Affective summary scores of sedation and stimulation for two alcohol participants across the timepoints.

The two figures above are used to explain the affective response that is associated with drinking. In the top figure, a normative affective response is shown for both sedating and 
stimulating properties of alcohol. In the bottom figure, the affective response is much more subdued on both the sedating and stimulating properties of alcohol. Timepoint 2 shows a peak response, however, all the other timepoints return to a non-affective response. This participant's behavioral data differed from the mean. Their affective response predicted their behavioral response. The study of alcohol's effects over time would be incomplete if subjective effects were not explored. Longitudinal studies have shown that expectancies are predictive of behavioral change (Leigh, 1989).

Although dose by time results for task performance were not consistently significant, the DEQ was used as a manipulation check at the end of the study. The alcohol group estimated that they consumed between 1 to 6 drinks, with an average of 3 drinks ( \pm 1 S.D.). The placebo group estimated that they received an average of 2 drinks $( \pm 1 \mathrm{SD})$ with a range between 0 to 3 drinks. Rank estimates using the Wilcoxon test show that there were significant differences between the groups, except for the question "how hard do you think you performed." and "how much do you think alcohol affected your performance on eye tracking"(see Figures 39-40). The questions that were asked at the end of the lab study indicate the alcohol group was aware that they had received alcohol. A Wilcoxon rank analysis was used since the drinking effects questions were ordinal. All the drinking effects questions were significantly different for the alcohol and control groups. The only question that was not significantly different was the item on how hard did you perform on the tasks. 


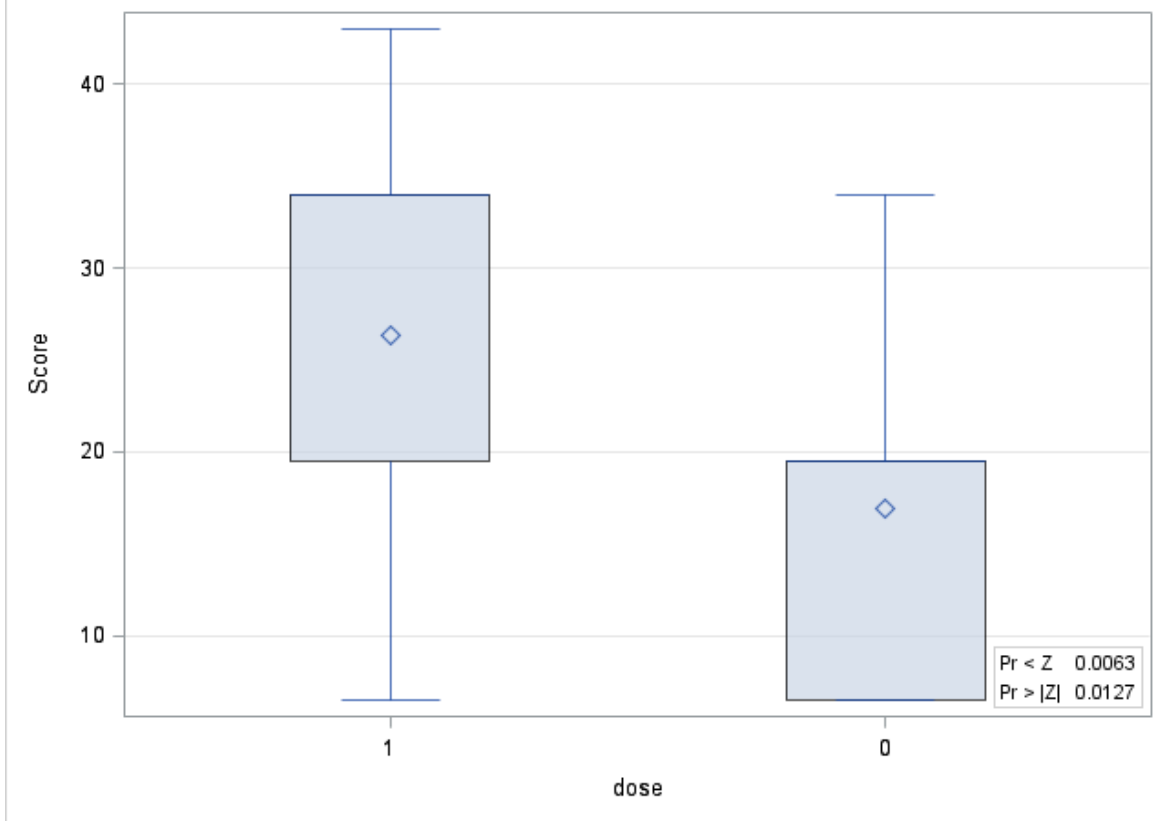

Figure 41: Wilcoxon plots of how groups felt at beginning of lab task

Figure 42: Wilcoxon plots of how groups felt after beverage consumption

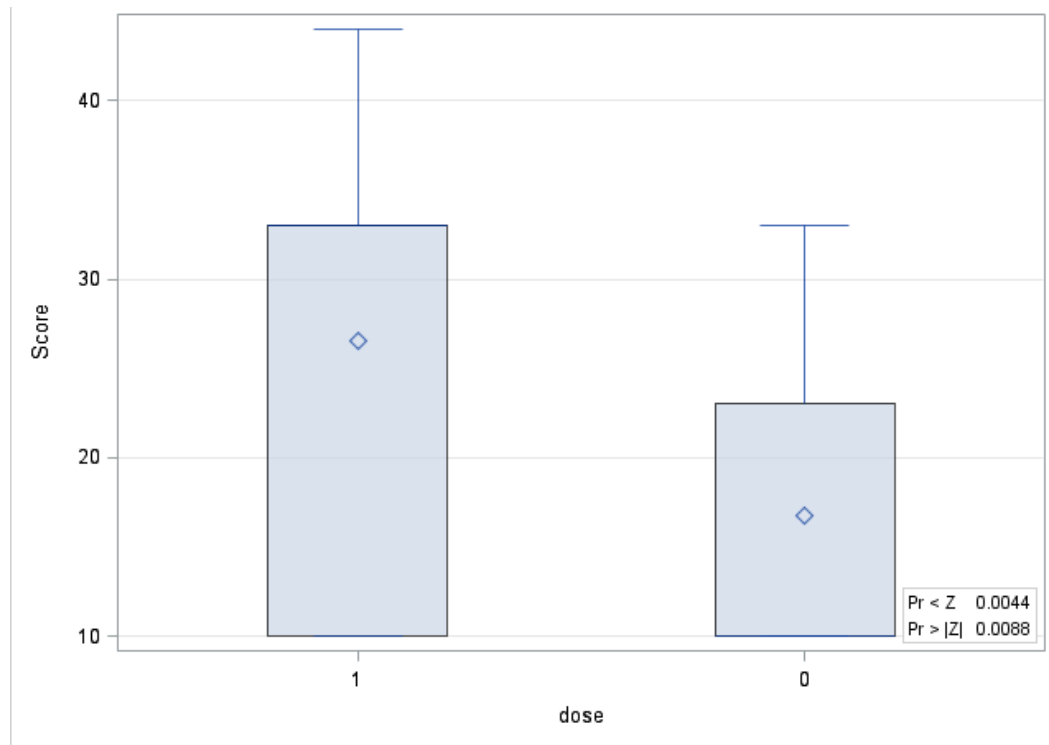


Figure 43. Wilcoxon plots of how groups felt at end of lab task

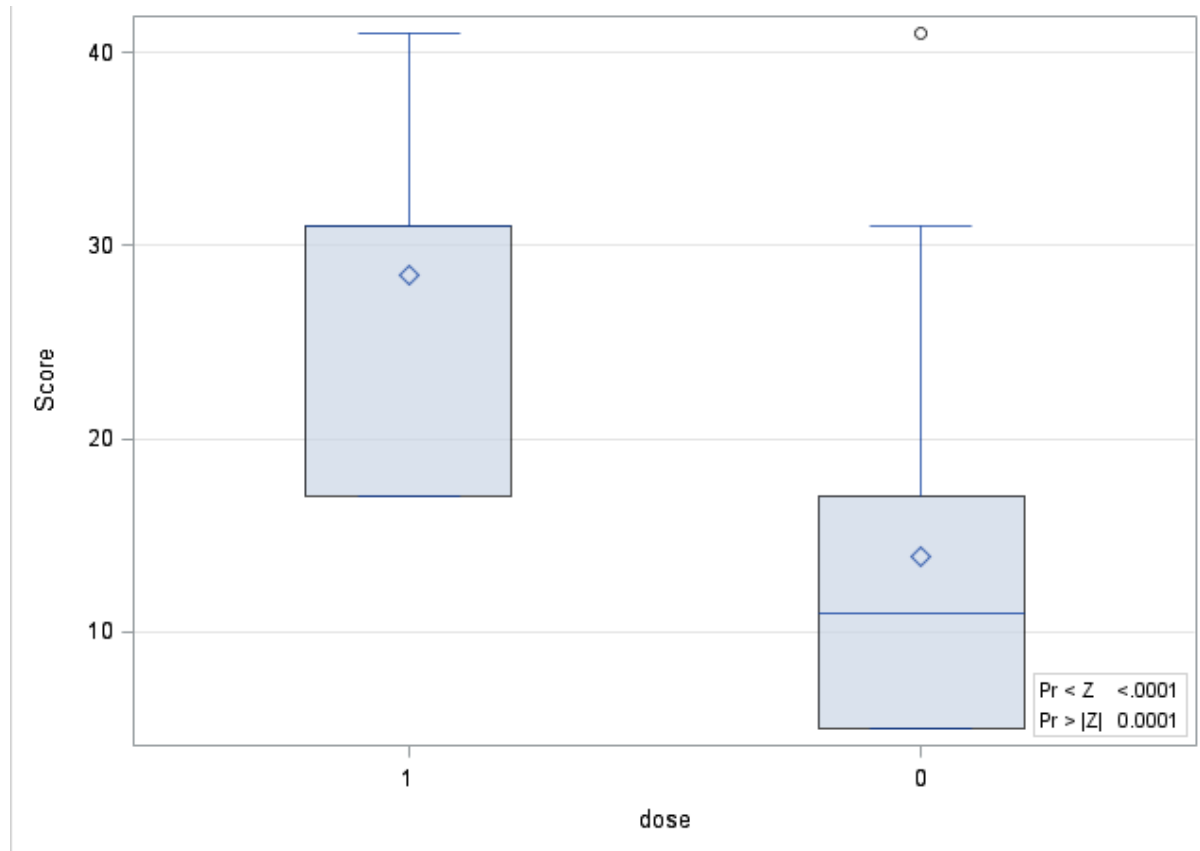

Figure 44. Wilcoxon plots of how hard groups tried to perform their best

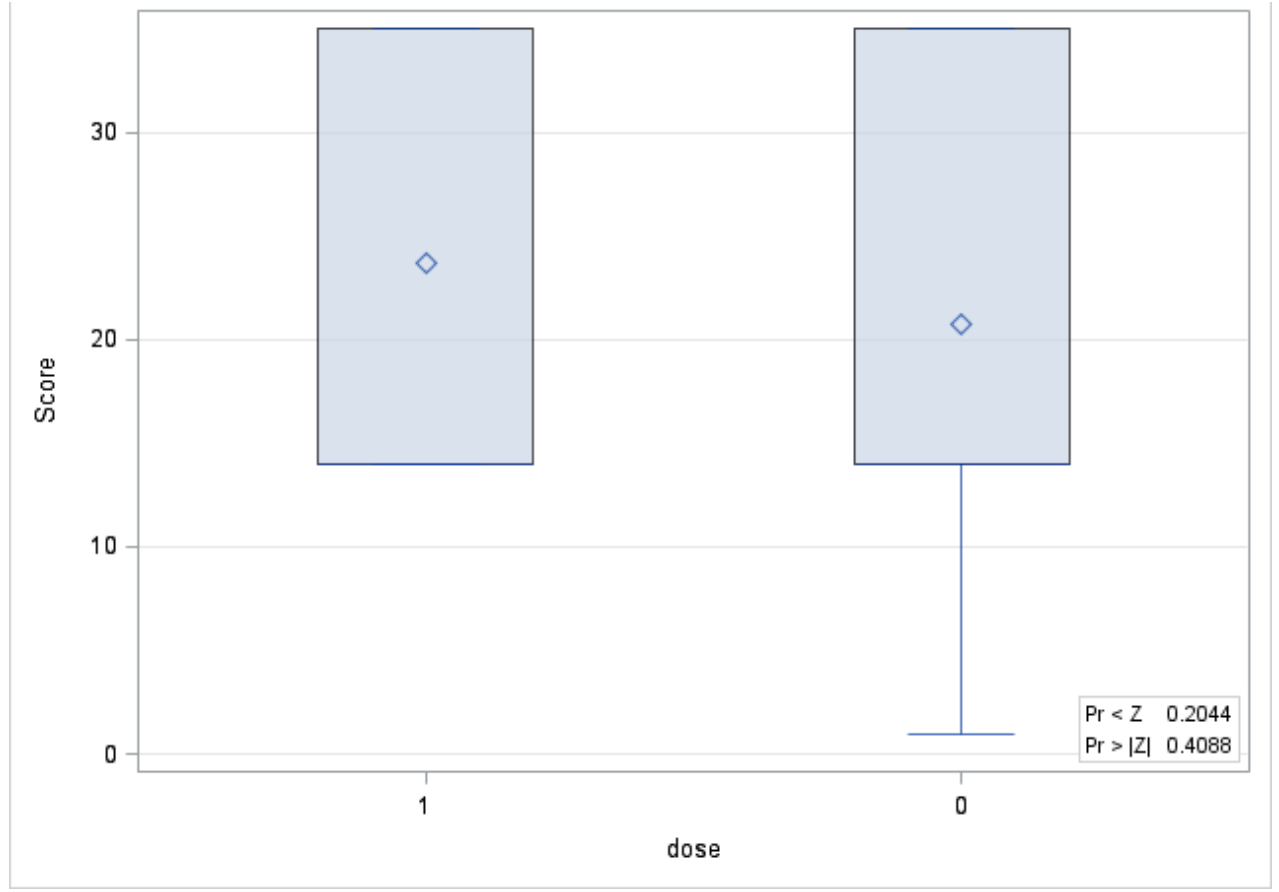


Figure 45. Wilcoxon plots of how alcohol affected performance on eye tracking

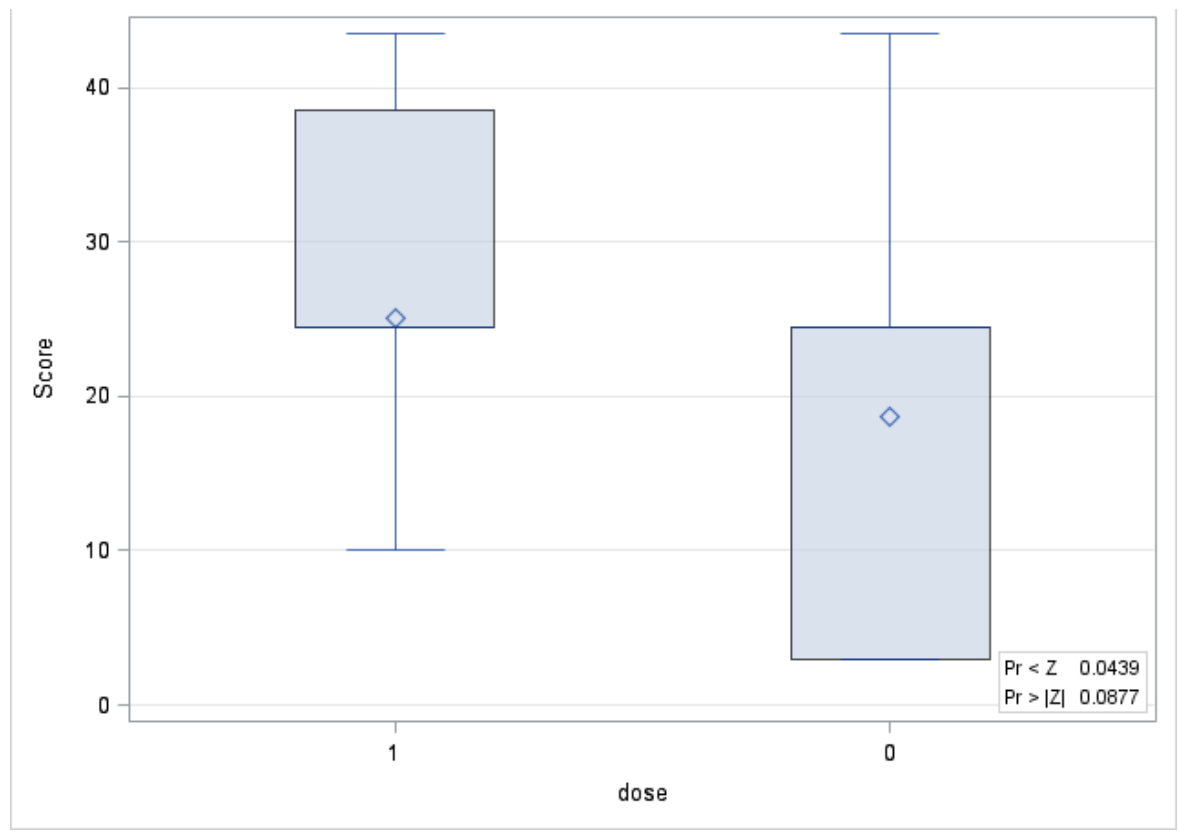

Figure 46. Wilcoxon plots of how alcohol affected performance on light recognition

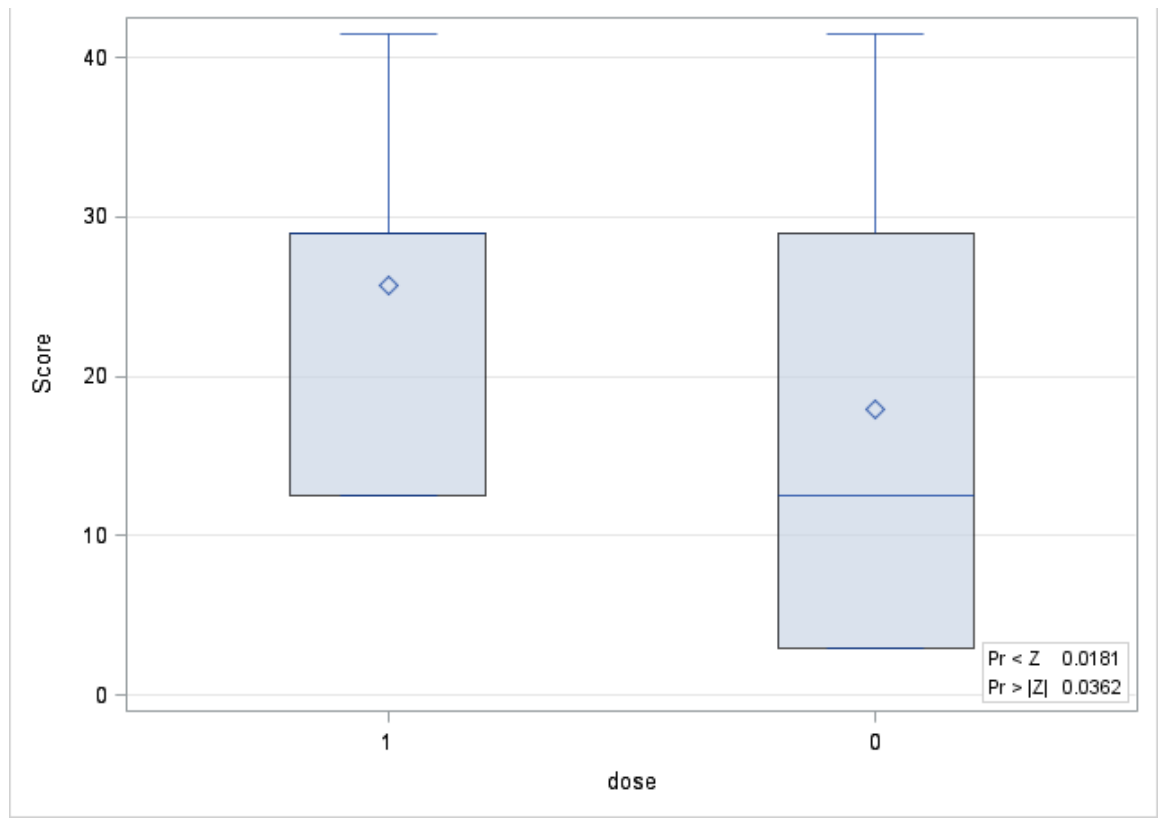


Figure 47. Wilcoxon plots of how alcohol affected effort in both tasks

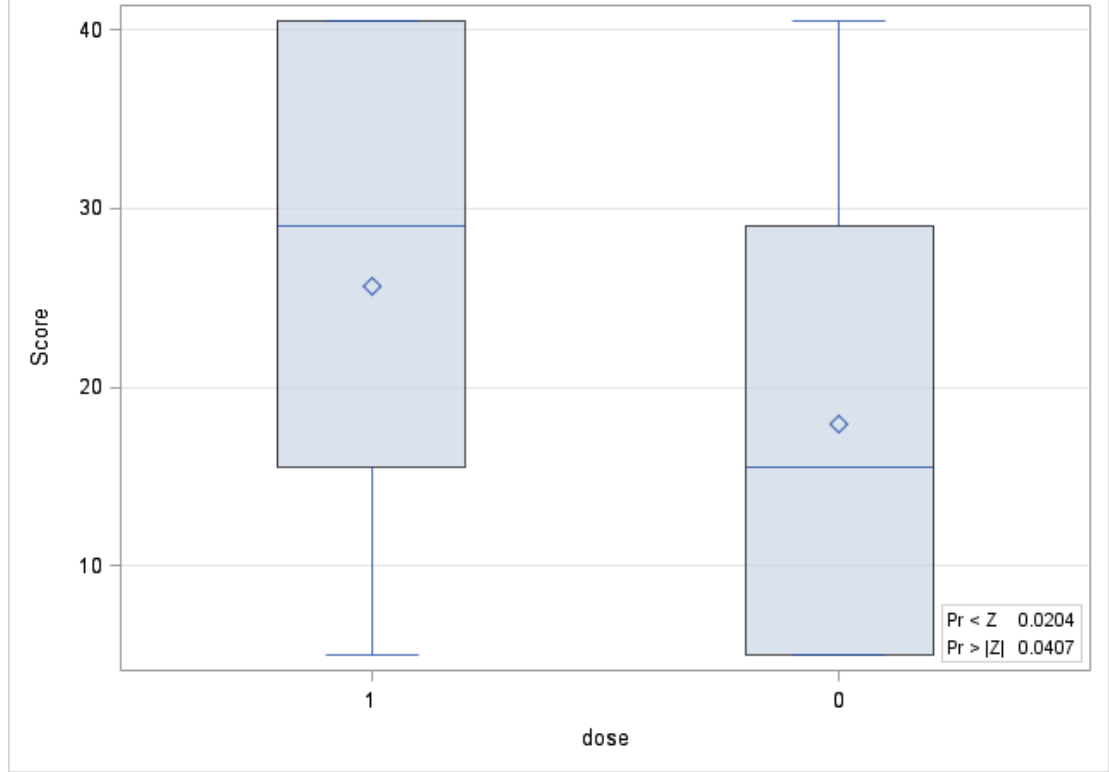

Figure 48. Wilcoxon plots of number of estimated drinks perceived consumed

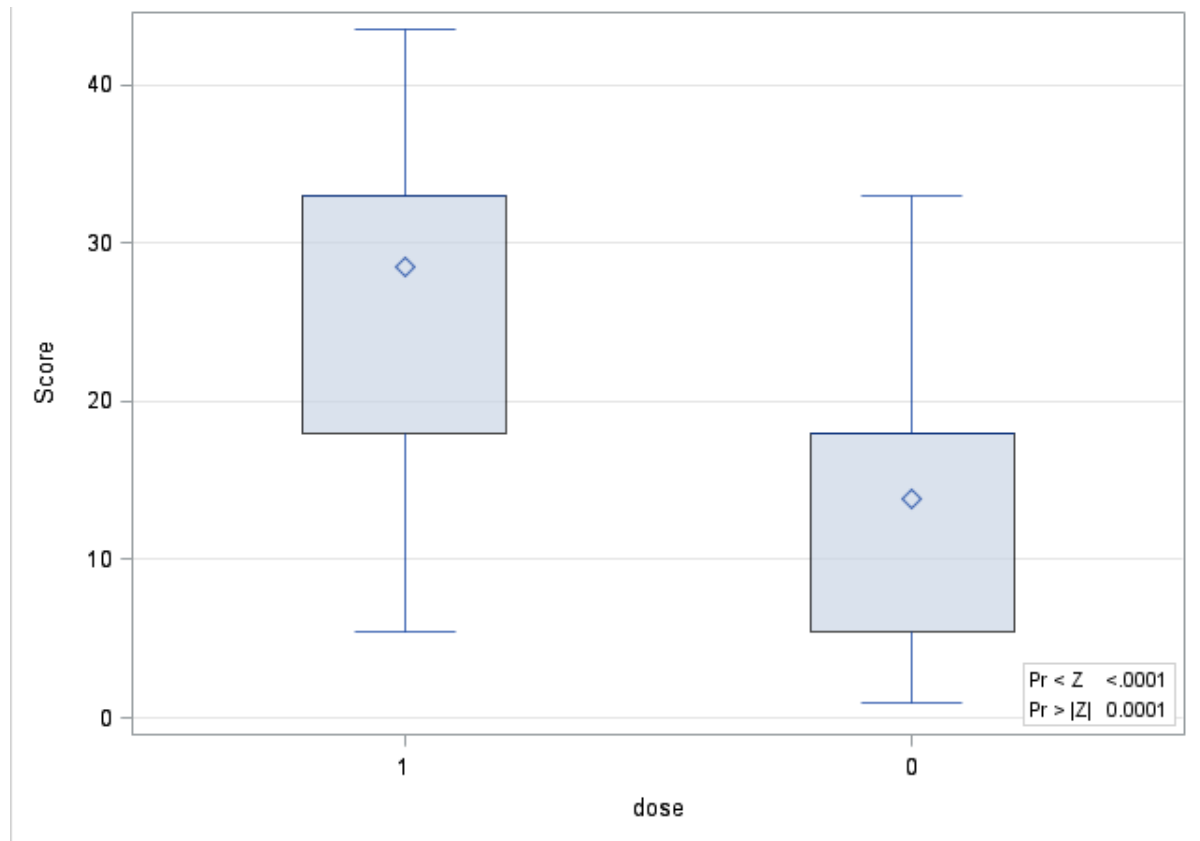

Data from the end of the absorption-elimination curve is necessary to assess whether these changes remain the same or change further over time. The individual 
differences on the alcohol curve are shown below for the 46 participants in this study

(Figure 49). Future studies can use a similar study design and address the declining alcohol dose.

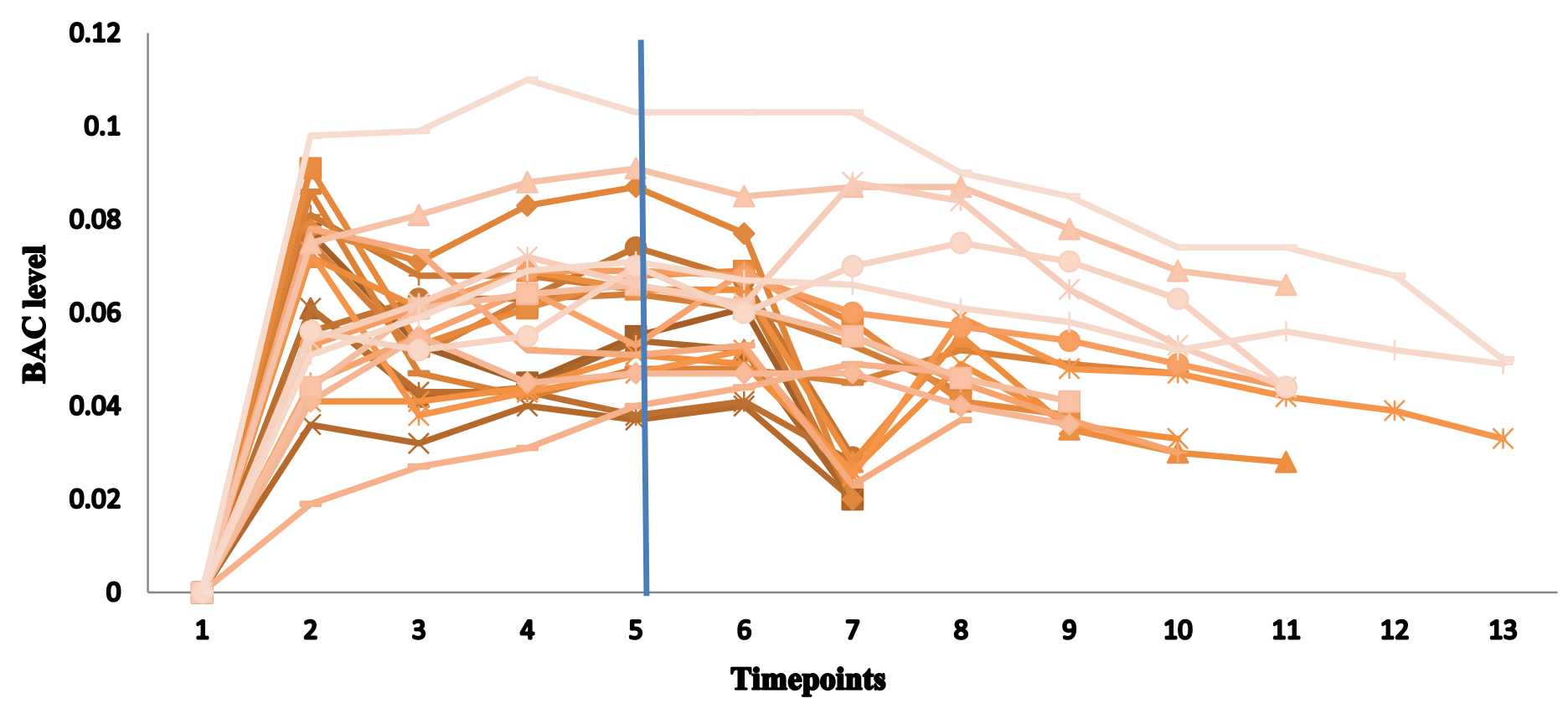

Figure 49. Overall trends in the alcohol dose at the individual level 


\section{Chapter 5}

\section{Discussion}

Attention is one of the most important processes in activities that depend on cognition. These activities include reading, writing, and driving. Selective attention and multitasking are common in our daily lives since so many events occur concurrently. This dissertation indicates that parallel tasks can become compromised by alcohol. The POC graphs showed consistent instruction and alcohol effects, with negative-sloping tradeoffs at least half of the time. However, in this study alcohol was not shown to produce a more severe attentional tradeoff between the two tasks in response to changes in attentional instruction, compared to placebo.

The research questions were: (1) How does alcohol affect a person's ability to perform two tasks at once? Alcohol has an effect on dual tasks; however, attention can be prioritized and mask actual declines in task performance. Alcohol also interference with the ability to shift attention between parallel tasks.

(2) How does this effect evolve over time as alcohol is metabolized? As alcohol is metabolized, response rates slow down, as observed in the light recognition task. The stimulating effects of alcohol disappear and performance becomes prone to error.

3) How does performance on the two tasks trade off in response to changes in attentional instructions? The attentional instructions aided in the dual task performance; however, there were significant declines in the light recognition task for the alcohol group even when the light recognition task was prioritized. 
(4) How does this tradeoff evolve over time as alcohol is metabolized? We would expect to see an increase in response time as alcohol is metabolized. Switching of attention becomes more difficult over time. Total information processing becomes compromised.

\section{Limitations}

Using breathalyzers in an alcohol lab study is convenient but not entirely accurate. Breathalyzers are prone to measurement error. The best tools to use are more invasive and more time-consuming. The acquired BAC levels in this study cannot be validated.

However, limitations of this eye tracking task include omission of a smooth pursuit task. Dwell times, which are, ameasured in smooth pursuit tasks, are important to measure and classify in eye tracking studies since they are highly predictive of . The eye tracking task in this studywas used to measure the saccades that occurred in the dual-task experiment.

These data were collected in a university setting and throughout the academic year. Although recruitment was adequate, incentives to participate in a research study were low. An increase in recruitment might have occurred if an incentive was included for participation in the study.

\section{Future research}

Other aims that we would have liked to examine are changes in voluntary control and executive functioning or reflexive functions. Although the alcohol group received a 
high alcohol dose that should have led to a decline in both reaction time and selective attention, the blocks of time might have been too long to achieve these aims. A future study could include a smooth pursuit task to measure how visual attention may change over time. Future studies can shorten these time frames or add distractors to increase anti saccades, where there might be more voluntary inhibition of responses to the tasks and stimuli. Performance was only studied on the ascending dose of the alcohol curve. A future study can use the same measures but study the effects of alcohol on both the ascending and declining curve. The trade-off for dual tasks, if taken during declining BAC levels, might have shown a greater effect.

The self-reported stimulant and sedative effects of alcohol are considered to be implicit measures of alcohol effects. The BAES reflects how individuals vary in how they report their expectations of alcohol. There were similar trends for both the alcohol and placebo groups. Alcohol expectations did not seem to predict the BAES subscales; however, based on the actual consumption ranks, differences were shown in their actual behavior. Attention or behavioral effects may be better predictors of alcohol effects. Acute tolerance enables speed to return; however, cognitive errors remain the same. The randomized alcohol and placebo design may have masked the implicit properties of alcohol effects since the placebo effect of alcohol was so great.

The focus of this study was on the relation between visual attention and cognitive and perceptual properties. Fixations were utilized to measurechange in vision and the impact of alcohol on change in vision under instructions how it changes after drinking alcohol. Our methods allowed us to look within blocks of time, for between group and within subject differences. The trade-off plots were used to relate successful eye fixation 
to recognition task performance, and the graphs may reveal a tradeoff between the two tasks. The tradeoff, or performance operating characteristic (POC) is important to understand since alcohol has a pronounced effect on attention. Future work can investigate the mediation of task performance and affective response in dual task performance. Acute tolerance might have allowed the participants to perform both tasks, and the motivational instructions might have also cued their attention to one task versus the other. 
Appendix A

\section{Multicultural component}

The effects of alcohol differ across genders. Men are able to absorb and metabolize more alcohol and at a faster rate than females. They have more water body volume and weigh more. Drinking patterns also differ across genders. Women who drink more than moderate level of alcohol are more susceptible to health risks according to the NIAAA. Risky behavior such as binge drinking is also greater in men. Racial and ethnic differences are also found in drinking rates. Hispanics, Blacks, Native Americans and low income groups are considered to experience more negative consequences of heavy drinking (NIAAA). Research on alcohol expectancies in different ethnic groups have also been developing.

Although a convenient sample will be collected at URI and in the surrounding Kingston area; active recruitment will be made for a diverse sample of students. The age group for this sample will not be a typical undergraduate sample since the study sample will include participants between the ages of 21 and 30 years old. At least $20 \%$ of the sample $(\mathrm{N}=60)$ will be recruited to include a diverse sample of men and women, and racial and ethnic groups.

Limited multicultural research has been done on attention and cognition; however, developmental studies with children and attention problems in urban settings have been more frequent (Mezzacappa, 2004). Subjective differences, such as "how sedated do you feel after drinking", are also found to differ across groups (Martin et al., 1993). Fmri studies have examined the role of cognitive control over eye movement (Dahl, 2008). The studies have looked at voluntarily controlling eye movements, and the ability to look away from a flashing light and instead look at a specific point away from the light, called an antisaccade movement. Although speed and accuracy of eye movements are matured in early adulthood, the ability to suppress automatic responses continued to improve in adolescence. The ability to direct gaze to a remembered location improved throughout adolescence (Dahl, 2008). These changes would be interesting to see in the proposed sample, especially in the use of the dual attention paradigm.

A representative sample was used to study age differences in cognitive daily tasks (Rast et al., 2008). Future invariance testing could include adding different ethnic or racial groups. The inclusion of a diverse sample and a broad age range adds a multicultural component to this research project. This is an important study that could be applied to larger and diverse samples in the study of attention and cognition. 


\section{References:}

Dahl, R.E. (2008). Biological, developmental, and neurobiological factors relevant to adolescent driving risks. American Journal of Preventative Medicine, 35(3S): S278S284.

Martin, C. S., Earleywine, M. Musty, R. E., Perrine, M. W., \& Swift, R. M. (1993). Development and validation of the biphasic alcohol effects scale. Alcoholism: Clinical and Experimental Research, 17(1), 140-146.

Mezaccappa, E. (2004). Alerting, orienting, and executive attention: developmental properties and sociodemographic correlates in an epidemiological sample of young, urban children. Child Development, 75(5), 1373-1386.

NIAAA (2013, January 30). Alcohol abuse and alcoholism. Retrieved from http://www.niaaa.nih.gov/alcohol-health/special-populations-co-occurringdisorders [special populations]

Rast, P., Zimprich, D., Bostel, M.V., \& Jolles, J. (2009). Factor structure and measurement invariance of the cognitive failures questionnaire across the adult life span. Assessment, 16(2), 145-158. 
Appendix B

Dosing algorithm

Curtin, J. J. \& Fairchild, B. A. (2003). Alcohol and cognitive control: Implications for regulation of behavior during response conflict. Journal of Abnormal Psychology, 112, 424-436.

The alcohol dose required to produce a specific peak BAL is a function of the participant's total body water (TBW), duration of the drinking period (DDP), time to peak BAL (TPB), and alcohol metabolism rate (MR). Specifically:

Alcohol dose $(\mathrm{g})=((10 * \mathrm{BAL} * \mathrm{TBW}) / 0.8)+(10 * \mathrm{MR} *(\mathrm{DDP}+\mathrm{TPB})) *(\mathrm{TBW} / 0.8)$

In the above formula, alcohol dose is measured in grams, BAL in g/100 ml (e.g., .010 $\mathrm{g} / 100 \mathrm{ml}$ ) DDP and TPB in hours and TBW in liters.

TBW is determined from gender-specific regression equations provided in: Watson, P. E. (1989). Total body water and blood alcohol levels: Updating the fundamentals. In K. Crow \& R. Batt (Eds.) Human metabolism of alcohol (Vol. 1): Pharmacokinetics, medicolegal aspects, and general interest (pp. 41-58). Boca Raton, FL: CRC Press. Specifically:

Men: TBW $(\mathrm{l})=2.447-0.09516 *$ AGE $($ years $)+0.1074 *$ HEIGHT $(\mathrm{cm})+0.3362 *$
WEIGHT $(\mathrm{kg})$

Women: TBW $($ I $)=-2.097+0.1069 *$ HEIGHT $(\mathrm{cm})+0.2466 *$ WEIGHT $(\mathrm{kg})$

Finally, alcohol dose is converted from grams to milliliters by dividing by the density of alcohol at $24^{\circ} \mathrm{C}, 0.7861 \mathrm{~g} / \mathrm{ml}$. 


\section{Appendix C}

Study Timeline

\begin{tabular}{|c|l|}
\hline Timeline & Task/Description \\
\hline $\begin{array}{c}0-10 \\
\text { mins. }\end{array}$ & $\begin{array}{l}\text { Report to Gilberth Hall for study, Provide informed consent, Participants (Pp) } \\
\text { randomized to low alcohol/ high alcohol/placebo condition. }\end{array}$ \\
\hline $\begin{array}{c}10-20 \\
\text { mins. }\end{array}$ & $\begin{array}{l}\text { Retest on critical inclusion/exclusion measures from telephone screening, } \\
\text { dietary compliance assessment, baseline breathalyzer and pregnancy test for } \\
\text { females. EYE CALIBRATION. } \\
\text { Demographics questionnaire, Alcohol expectancy questionnaire (AEQ), and } \\
\text { the Cognitive failures questionnaire (CFQ), Biphasic Alcohol scale (BAES), } \\
\text { and the Visual Analogue Scale (VAS) will be administered. Baseline task eye } \\
\text { tracking/attention task will be conducted with verbal instructions. }\end{array}$ \\
\hline 20-40 mins. & $\begin{array}{l}\text { Post drink1 } \\
\text { BAES and VAS will be administered. } \\
\text { Eye tracking/ attention lab task conducted post-beverage. }\end{array}$ \\
\hline $40-60$ mins. & $\begin{array}{l}\text { Post drink2 } \\
\text { BAES and VAS will be administered. } \\
\text { Eye tracking/ attention lab task conducted. }\end{array}$ \\
\hline $60-80$ mins. & $\begin{array}{l}\text { Postdrink3 } \\
\text { BAES and VAS will be administered } \\
\text { Eye tracking/ attention lab task conducted post-beverage. }\end{array}$ \\
\hline $80-100$ & $\begin{array}{l}\text { Post drink4 } \\
\text { BAES and VAS will be administered } \\
\text { Eye tracking/ attention lab task conducted post-beverage. }\end{array}$ \\
\hline $100-120$ & $\begin{array}{l}\text { End lab } \\
\text { Drinking effects questionnaire (DEQ) will be administered. } \\
\text { Debrief } \\
\text { Pp in placebo condition are dismissed. Those receiving alcohol will be } \\
\text { retained in a comfortable room with computer, TV/DVD, magazines, } \\
\text { newspapers, snacks and soft drinks until their blood alcohol level = .02, at } \\
\text { which point they will be dismissed. }\end{array}$ \\
\hline
\end{tabular}

\section{List of Measures}

The Alcohol Use Disorders Identification Test (AUDIT) ((Saunders et al., 1993): this diagnostic questionnaire wasused to screen for any alcohol dependency or abuse.

Participantsonly included those who scored 15 or less. The AUDIT will be administered on the telephone as part of the screening for eligibility/ ineligibility. 
Demographics Questionnaire: the questionnaire asked about age, education, normative vision, and daily alcohol intake. This questionnaire was asked at the beginning of the session, or at baseline.

The Alcohol Expectancy Questionnaire (AEQ) (Brown et al., 1987; George et al., 1995): The AEQ has been used to measure behavioral outcomes related to alcohol expectancies. It is composed of 6 factors: global positive change, sexual enhancement, physical and social pleasure, increased social assertiveness, relaxation and tension reduction, arousal and aggression. It has been used in both adolescent and adult samples. Coefficient alphas range from .72-.92 with a mean of .84. Test-retest reliability is set at .64. The AEQ was administered once, at baseline.

The Cognitive Failures Questionnaire (CFQ) (Broadbent et al., 1982): this is a self-report questionnaire that is used to assess failures in perception, memory, and motor function. It correlates with the Mental Health Questionnaire or MHQ. The CFQ wasadministered at baseline.

The Biphasic Alcohol Scale (BAES) (Martin et al., 1993): is a self-report measure, used to measure both the stimulant and sedative effects of alcohol. It has been used in samples of all ages. Cronbach's alpha ranges from 0.85- 0.94. The BAES wasadministered at every timepoint during the experiment.

The Visual Analogue Scale (VAS): the visual analogue scale is used to quantify craving on a continuum of values. It has been used to measure pain ranging from no pain to very severe pain. This questionnaire was administered at every timepoint along with the BAES.

Drinking effects questionnaire (DEQ): this is a self-report questionnaire that was used as a manipulation check. This questionnaire was administered once at the end of the study. 


\section{Bibliography}

Abroms, B.D., Fillmore, M.T., Marczinski, C.A. (2003). Alcohol-induced impairment of behavioral control: effects on alteration and suppression of prepotent responses. Journal of Studies on Alcohol, 64, 687-695.

Abroms, B.D., Gottlob, L.R., \& Fillmore, M.T. (2006). Alcohol effects on inhibitory control of attention: distinguishing between intention and automatic mechanisms. Psychopharmacology, 188, 324-334.

Barnes, G.R. (1984). The effects of ethyl alcohol on visual pursuit and suppression of the vestibulo-ocular reflex. Acta Otolaryngol (Stockh) Supplement, 406, 161-166.

Broadbent, D. E., Cooper, P.F., FitzGerald, P., \& Parks, K. R. (1982). The cognitive failures questionnaire (CFQ) and its correlates. British Journal of Clinical Psychology, 21, 1-16.

Brown, S. A., Christiansen, B. A., \& Goldman, M. S. (1987). The alcohol expectancy questionnaire: An instrument for the assessment of adolescent and adult alcohol expectancies. Journal of Studies on Alcohol, 48(5), 483-491.

Brown, S.A., Goldman, M.S., Inn A., \& Anderson L.R. (1980). Expectations of reinforcement from alcohol: their domain and relation to drinking patterns. Journal of Consulting and Clinical Psychology, 48(4), 419-426.

Brumback, T., Cao, D., \& King, A. (2007). Effects of alcohol on psychomotor performance and perceived impairment in heavy binge social drinkers. Drug and Alcohol Dependence, 91, 10-17. 
Cheal, M., \& Lyon, D.R. (1991). Central and peripheral recuing of forced-choice discrimination. The Quarterly Journal of Experimental Psychology, 43A (4), 859880.

Connor, J.P., Young, R.M., Williams, R.J., \& Ricciardelli, L.A. (2000). Drinking restraint versus alcohol expectancies: which is the better indicator of alcohol problems? Journal of Studies on Alcohol, 61, 353-359.

Dougherty, D., Marsh, D., Moeller, F., Chokshi, R., \& Rosen, V. (2006). Effects of moderate and high doses of alcohol on attention, impulsivity, discriminability, and response bias in immediate and delayed memory task performance. Alcoholism: Clinical and Experimental Research, 24(11), 1702--1711.

Fell, J.C., \& Voas, R.B. (2006). The effectiveness of reducing illegal blood alcohol concentration (BAC) limits for driving: evidence for lowering the limit to .05 BAC. Journal of Safety Research, 37, 233-243.

Field, M., Wiers, R.W., Christiansen, P., Fillmore, M.T., \& Verster, J.C. (2010). Acute alcohol effects on inhibitory control and implicit cognition: implications for loss of control over drinking. Alcoholism: Clinical and Experimental Research, 34(8), 1346-1352.

Fogarty, J.N., \& Vogel-Sprott, M. (2002). Cognitive processes and motor skill differ in sensitivity to alcohol impairment. Journal of Studies on Alcohol, 63, 404-411.

George, W.H., Frone, M.R., Cooper, M.L., Russell, M., Skinner, J.B., \& Windle, M. (1995). A revised alcohol expectancy questionnaire: factor structure confirmation 
and invariance in a general population sample. Journal of Studies on Alcohol, 56, 177-185.

George, W. H., Raynor, J. O., \& Nochajski, T. H. (1990). Resistance to alcohol impairment of visual-motor performance II: effects for attentional set and selfreported concentration. Pharmacology Biochemistry \& Behavior, 36, 261-266.

George, W. H., Raynor, J. O., \& Nochajski, T. H. (1992). Resistance to alcohol impairment of visual-motor performance: does it help to pay attention. Journal of Studies on Alcohol, 53, 507-513.

Hill, J. C., \& Toffolon, G. (1990). Effect of alcohol on sensory and sensorimotor visual functions. Journal of Studies on Alcohol, 51(2), 108-113.

Holdstock, L., \& de Wit, H. (1999). Ethanol impairs saccadic and smooth pursuit eye movements with producing self-reports of sedation. Alcoholism: Clinical and Experimental Research, 23(4), 664-672.

Hull, J.G., \& Bond, C.F. (1986). Social and behavioral consequences of alcohol consumption and expectancy: a meta-analysis. Psychological Bulletin, 99(3), 347-360.

Koelega, H.S. (1995). Alcohol and vigilance performance: a review. Psychopharmacology, 118, 233-249.

Kreusch, F., Vilenne, A., \& Quertemont, E. (2013). Assessing the stimulant and sedative effects of alcohol with explicit and implicit measures in a balanced placebo design. Journal of Study on Alcohol and Drugs, 74, 923-930. 
Leigh, B.C. (1989). In search of the seven dwarves: issues of measurement and meaning in alcohol expectancy research. Psychological Bulletin, 105(3), 361-373.

Maple-Horvat, D.E.,Cooper,H.L., Gilbey,S.L., Watson, J.C., Mehta, N., Kaur-Mann, D., ...Keil, D. (2008). Alcohol badly affects eye movements linked to steering, providing for automatic in-car detection of drunk driving. Neuropsychopharmacology, 33, 849-858.

Martin, C.S., \& Earlewine,M. (1990). Ascending and descending rates of change in blood alcohol concentrations and subjective intoxication ratings. Journal of Substance Abuse, 2, 345-352.

Martin, C. S., Earleywine, M., Musty, R. E., Perrine, M. W., \& Swift, R. M. (1993). Development and validation of the biphasic alcohol effects scale. Alcoholism: Clinical and Experimental Research, 17(1), 140-146.

McSorley, E., \& Findlay, J. M. (2001). Visual search in depth. Vision Research, 41, 3487-3496.

Mellanby E. (1919). Alcohol: its absorption into and disappearance from the blood under different conditions. (Special Report Series Monograph No. 31) London, Medical Research Committee.

Miyake, A., Friedman, N. P., Emerson, M. J., Witzkin, A. H., Howerter, A., \& Wager, T. D. (2000). The unity and diversity of executive functions and their contributions to complex "frontal lobe" tasks: a latent variable analysis. Cognitive Psychology, 4, 49-100. 
Moskowtiz, H. \& Sharma, S. (1974). Effects of alcohol on peripheral vision as a function of attention. Human Factors, 16(2), 174-180.

Navon, D., \& Gopher, D. (1979). On the economy of the human-processing system. Psychological Review, 86(3), 214-255.

Nicholson, M. E., Andre, J. T., Richard, A. T., Wang, M., \& Leibowitz, H. W. (1995). Effects of moderate dose alcohol on visual contrast sensitivity for stationary and moving targets. Journal of Studies on Alcohol, 56, 261-266.

Peck, R.C., Gebers, M.A., Voas, R.B., \& Romano, E. (2008). The relationship between blood alcohol concentration (BAC), age, and crash risk. Journal of Safety Research, 39, 311-319.

Post. R.B., Lott, L.A., Maddock, R.J. \& Beede, J.I. (1996). An effect of alcohol on the distribution of spatial attention. Journal of Studies on Alcohol, 57, 260-266.

Post, R. B., Tavano, L. A., \& Maddock, R. J. (1997). Role of feedback in formation of acute tolerance to alcohol. Journal of Studies on Alcohol, 59, 723-730.

Saunders, J. B., Aasland, O. G., Babor, T. F., De La Fuente, J. R. and Grant, M. (1993), Development of the Alcohol Use Disorders Identification Test (AUDIT): WHO Collaborative Project on Early Detection of Persons with Harmful Alcohol Consumption-II. Addiction, 88: 791-804. 
Schneider, W.X. (1995). VAM: a neuro-cognitive model for visual attention control for segmentation, object recognition, and space-based motor action. Visual Cognition, 2(2), 331-376.

Schweizer, T., \& Vogel-Sprott, M. (2008). Alcohol-impaired speed and accuracy of cognitive functions: A review of acute tolerance and recovery of cognitive performance. Experimental and clinical psychopharmacology, 16(3), 240.

Schweizer, T., Vogel-Sprott, M., Danckert, J., Skakum, A., \& Broderick, C. (2006). Neuropsychological profile of acute alcohol intoxication during ascending and descending blood alcohol concentrations. Neuropsychopharmacology, 31, 13011309.

Smith, E..E. (1968). Choice reaction time: an analysis of the major theoretical positions. Psychological Bulletin, 69(2), 77-110.

Sperling, G., \& Melchner, M.J. (1978). The attention operating characteristic: examples from visual search. Science, New Series, 202(4365), 315-318.

Stapleton, J. M., Guthrie, S., \& Linnoila, M. (1986). Effects of alcohol and other psychotropic drugs on eye movements: relevance to traffic safety. Journal of Studies on Alcohol, 47(5), 426-432.

Steele, C. M., \& Josephs, R. A. (1990). Alcohol myopia: its prized and dangerous effects. American Psychologist, 45(8), 921-933. 
Tedstone, D., \& Coyle, K. (2004). Cognitive impairments in s sober alcoholics: performance on selective and divided attention tasks. Drug and Alcohol Dependence, 75, 277-286.

Tiplady, B., Baird, R., Lütcke, H., Drummond, G., \& Wright, P. (2005). Effects of ethanol on kinaesthetic perception. Journal of Psychopharmacology, 19(6), 627632.

Tzambazis, K., \& Stough, C. (2000). Alcohol impairs speed on information processing and simple and choice reaction time and differentially impairs higher-order cognitive abilities. Alcohol \& Alcoholism, 35(2), 197-201.

Vogel-Sprott M., \& Fillmore M.T. (1993). Impairment and recovery under repeated doses of alcohol: effects of response outcomes. Pharmacology Biochemistry and Behavior, 45(1), 59-63.

Wechsler, H., Davenport, A., Dowdall, G., Moeykens, B., \& Castillo, S. (1994). Health and behavioral consequences of binge drinking in college: a national survey of students at 140 campuses. The Journal of American Medical Association, 272(21), 1672-1677.

Wickens, C.D. (1976). The effect of divided attention on information processing in tracking. Journal of Experimental Psychology: Human Perception and Performance, 2, 1-13.

Zador, P.L., Krawchuk, S.R., \& Voas, R.B. (2000). Alcohol-related relative risk of driver fatalities and driver involvement in fatal crashes in relation to driver age and gender: an update using 1996 data. Journal of Studies on Alcohol, 61, 387395. 